Portland State University

PDXScholar

Spring 8-27-2013

\title{
The Effects of Offender Age and Offender-Victim Relationship on Modus Operandi Strategies to Lure the Victim
}

Hayley Lauren Tews

Portland State University

Follow this and additional works at: https://pdxscholar.library.pdx.edu/open_access_etds

Part of the Clinical Psychology Commons, Criminology Commons, and the Personality and Social Contexts Commons

Let us know how access to this document benefits you.

\section{Recommended Citation}

Tews, Hayley Lauren, "The Effects of Offender Age and Offender-Victim Relationship on Modus Operandi Strategies to Lure the Victim" (2013). Dissertations and Theses. Paper 1040.

https://doi.org/10.15760/etd.1040

This Thesis is brought to you for free and open access. It has been accepted for inclusion in Dissertations and Theses by an authorized administrator of PDXScholar. Please contact us if we can make this document more accessible: pdxscholar@pdx.edu. 
The Effects of Offender Age and Offender-Victim Relationship on

Modus Operandi Strategies to Lure the Victim

\title{
by
}

Hayley Lauren Tews

A thesis submitted in partial fulfillment of the requirements for the degree of

\author{
Master of Science \\ in \\ Psychology
}

Thesis Committee:

Keith Kaufman, Chair

Andrew Mashburn

Greg Townley

\section{Portland State University}

2013 


\begin{abstract}
Research on the modus operandi ("method of operation") of child sexual abuse (CSA) offenders has been useful in informing successful prevention programs (LeClerc, 2009). However, a gap in the literature regarding the strategies offenders use to lure potential CSA victims still remains. The present study seeks to examine the effects of offendervictim relationship and offender age on the use of strategies to lure victims for the purpose of committing CSA. Data for this study is taken from a larger investigation which included 854 identified adolescent and adult CSA offenders from nine different states. A 2 X 2 MANCOVA analysis revealed significant group differences for the each of the subgroups of interest in their use of threats and coercion to lure victims for the purpose of committing CSA. More specifically, it was found that adolescent CSA offenders utilize threats and coercion with a greater frequency than adult CSA offenders and intra-familial CSA offenders utilize threats and coercion with a greater frequency than extra-familial CSA offenders. Follow up analyses at the item level indicated group differences on multiple items (i.e., specific strategies) comprising the subscales used. The implications of these findings for treatment and prevention work in this area are discussed, as are policy impacts. Finally, suggestions for future research are provided.
\end{abstract}




\section{Acknowledgements}

I would like to thank my advisor, Dr. Keith Kaufman, for his support and guidance throughout this process. Additionally, I would like to thank Dr. Andy Mashburn and Dr. Greg Townley for their participation on my thesis committee and their support and suggestions throughout the development and completion of this project. Finally, I would like to thank my family. Their unending support and encouragement was critical throughout this process. 
Table of Contents

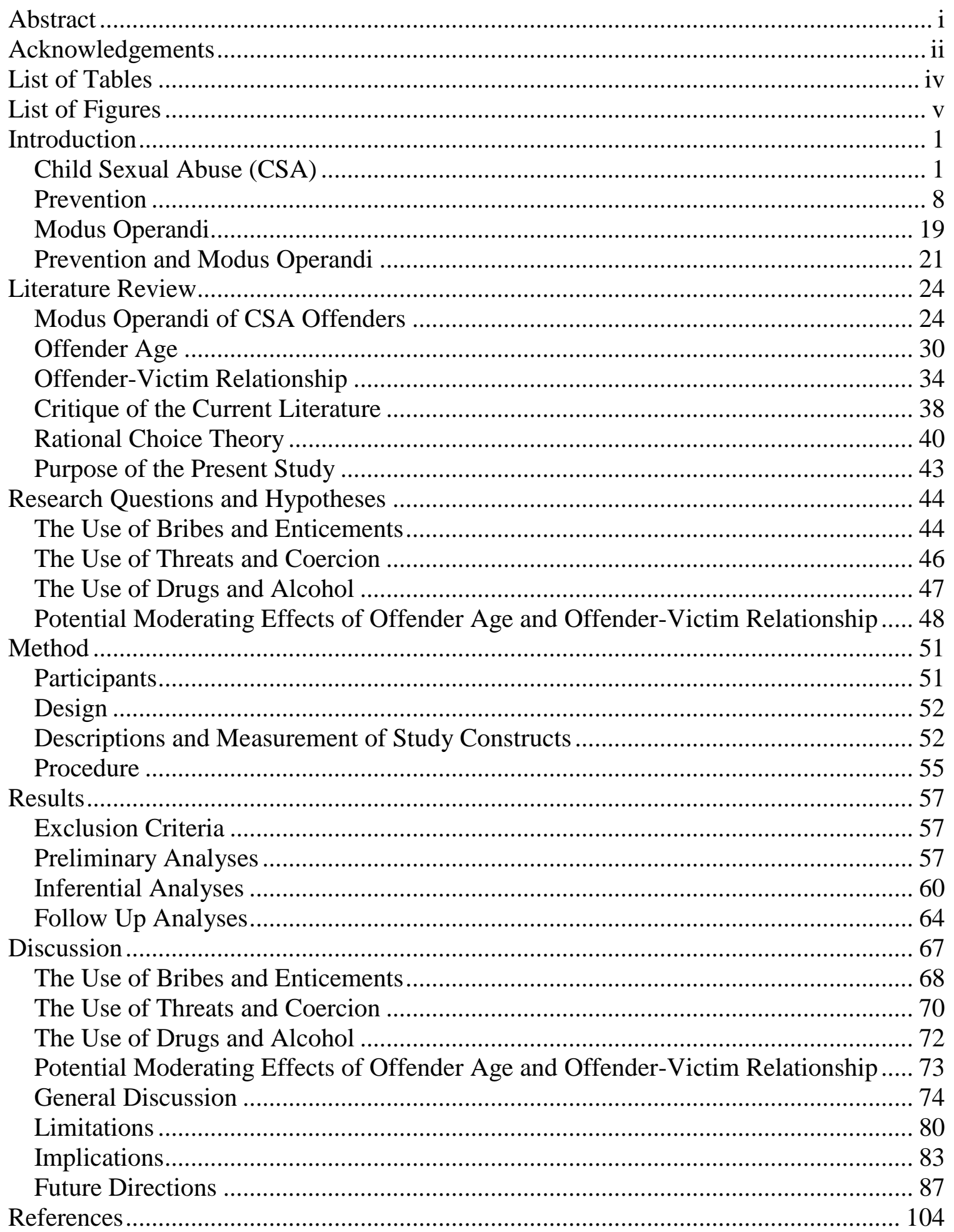


List of Tables

Table 1.

Subgroup Cell Sizes

Table 2.

Luring the Victim to the Abuse Site Subscales

Table 3.

Group Means for the 'Bribes and Enticements', 'Threats and Coercion', and 'Drugs and Alcohol' Subscales

Table 4.

Percent Endorsement of Items by Adolescent and Adult CSA Offenders

Table 5.

Percent Endorsement of Items by Intra- and Extra-familial CSA Offenders

Table 6.

$t$-test of Group Differences in Adolescent and Adult CSA Offenders on Selected Items

Table 7.

$t$-test of Group Differences in Intra- and Extra-familial CSA Offenders on Selected Items 
List of Figures

Figure 1.

The Ecological Model

Figure 2.

Moderation Model (Hypotheses 3a and 3b)

Figure 3.

102

Mean 'Threats and Coercion' Subscale Scores as a Function of Offender Age

Figure 4.

103

Mean 'Threats and Coercion' Subscale Scores as a Function of Offender-Victim Relationship 


\section{Introduction}

\section{Child Sexual Abuse (CSA)}

Child sexual abuse (CSA) is a problem that has been identified as national health problem. The Centers for Disease Control and Prevention and the World Health Assembly have recognized CSA as one of the forms of violence that puts the public health at the greatest risk due to its short- and long-term physical and psychological effects on the victim, the victim's families, and the community (McMahon \& Puett, 1999). The World Health Organization (WHO) has collaborated with the International Society for the Prevention of Child Abuse and Neglect (IPSCAN) to capture the general aspects of the problem in the following definition of CSA:

"...the involvement of a child in sexual activity that he or she does not fully comprehend, is unable to give informed consent to, or for which the child is not developmentally prepared, or else that violates the laws or social taboos of society. Children can be sexually abused by adults or other children who are - by virtue of their age or stage of development - in a position of responsibility, trust or power over the victim (WHO, 2006 p. 10).”

Unfortunately, similar to other types of sexual assault, CSA remains vastly underreported (Johnson, 2004). There is wide agreement within the field that, due to underreporting, official estimates do not reflect the actual incidence of CSA (Smallbone, Marshall, \& Wortley, 2008). Even so, it has been estimated to affect approximately $32 \%$ of girls and $13 \%$ of boys before they reach the age of 16 (Elliot \& Briere, 1995). Victims of CSA experience a variety of detrimental effects that may continue into adulthood including, but not limited to: physical consequences, long-term depression and post-traumatic stress (Beitchman, Zucker, Hood, DaCosta, Akman, and Cassavia, 1992; Johnson, 2004; 
McMahon \& Puett, 1999; Paolucci, Genuis, \& Violato, 2001). Victims of CSA also experience self-esteem issues and may engage in reactive abuse (i.e., a victim of CSA perpetrates CSA against a new victim; Johnson, 2004). Many experts agree that more effective preventive efforts are necessary to address CSA. In the following sections, CSA will be described in greater detail. In addition, prevalence rates and the consequences of victimization will be presented.

Defining child sexual abuse. Child sexual abuse is a social construction that is uniquely defined by the society in which it occurs and therefore, is difficult to define with precision (Bolen, 2001). In fact, definitions of CSA are inconsistent across research studies and lawful jurisdictions making it difficult to compare systematic research and create a comprehensive body of literature to move the CSA field forward (Rowan, 2006). Variability in definitions can occur across multiple dimensions that constitutes CSA. The range of behaviors that are considered CSA cover the offender exposing his ${ }^{1}$ genitalia (i.e., "noncontact abuse") to vaginal and anal penetration (i.e., "contact abuse"). For example, Russell (1983) found vastly different rates of abuse by altering how she defined CSA in her study. When the definition included noncontact offenses, she found that $48 \%$ of the females in her sample had experienced CSA before the age of 14 . When the definition was limited exclusively to contact offenses, she found that $28 \%$ of females in her sample had experienced CSA before the age of 14. In addition, the way in which each of these acts is carried out can vary (e.g., one time only vs. multiple incidents of contact abuse). Another important component of the definition of CSA is how the relationship

\footnotetext{
${ }^{1}$ It is acknowledged that CSA can also be perpetrated by women. Offenders are referred to as "him" throughout this paper due to the focus of the analyses of the present study and finding that most CSA offenders are male (Cortoni \& Hanson, 2005; Smallbone, Marshall, \& Wortley, 2008).
} 
between the victim and the offender is defined (e.g., intra-familial [i.e., within the family], extra familial [i.e., outside of the family]; Bolen, 2001; Russell, 1983). Further, including some form of an age criterion has been important in defining abuse because it greatly reduces the probability that innocent, consensual, sexual exploration between same age peers is labeled as abuse. For example, definitions of what constitutes CSA can vary by the age differential between the victim and the offender. In many states, if the victim is more than three years younger than the offender, the law indicates that CSA has occurred (Bolen, 2001). The age of the victim has also often been used as a criterion to identify CSA (e.g., sexual contact with a victim under the age of 12). In general, definitions (i.e., from both research and the legal profession) require two elements for an act to be labeled as CSA: (1) involving a child in sexual activities and (2) the presence of an "abusive condition" which may involve coercion that implies that the act was not consensual or that the victim was too young to give consent (Finkelhor, 1994). As has been made evident, such variability in the definition of CSA across research programs and lawful jurisdictions may be problematic as the field moves forward.

The greatest implications for using different criterion (e.g., age, type of abuse, offender-victim relationship) in defining abuse is the potential that a more conservative definition is likely to ignore legitimate cases of CSA (Bolen, 2001). Conversely, liberal definitions will likely label acts such as sexual exploration between similarly aged minors as CSA. Finally, it has been suggested that it is difficult to define an act that has such great amounts of situational variability, such that no two perpetrations of CSA may be the same (Bolen, 2001). 
In addition to legal implications, the variability of the definition of CSA used in different research programs has made comparisons across studies difficult. As evident from this discussion, compiling accurate, comprehensive incidences of CSA is a challenging endeavor because systematic research programs who use different definitions of CSA are not directly comparable. Efforts have been undertaken by the United States Department of Health and Human Services to systematically investigate rates of child maltreatment in general and CSA specifically. Federally funded national incidence studies represent an effort to better understand the incidence and prevalence of child maltreatment based on national reporting systems using consistent definitions.

Incidence of child sexual abuse. The Fourth National Incidence Study (NIS-4) is the fourth installment in an effort by the United States Department of Health and Human Services to investigate the rates of child maltreatment (Sedlak, Mettenburg, Basena, Petta, McPherson, Greene, \& Li, 2010). The NIS-4 was congressionally mandated to conduct this investigation by the Keeping Children and Families Safe Act of 2003 and collected information from 126 child protective service agencies serving 122 counties. In addition, the NIS-4 also collected data from 1,524 sentinel agencies such as: sheriff's departments, departments of juvenile probation, hospitals, shelters, day care centers, etc. Data for this project was collected from December 2005 to May 2006. Between 135,300 and 180,500 (22-24\%) individuals from this sample experienced some form of CSA depending on which "Standard of Harm" is being used. Almost half (42\%) of the children who experienced CSA were sexually abused by someone other than a parent (biological or non-biological) or a parent's partner and 36\% were abused by a biological parent. 
Finally, a vast majority of the offenders were male (87\%). Overall, the data collected for the NIS-4 revealed declines in the estimated number of sexually abused children from the NIS-3 previously collected in 1993. This represented a 38-40\% decrease from the NIS-3 (1993). Although it appears that there is a decline in CSA overall, it continues to be a significant public health concern. In addition, it is important to recognize that there may be factors other than fewer numbers of actual CSA cases (e.g., naiveté of children, lack of communication and social skills, victim blaming) that may be driving this decline.

As previously mentioned, similar to other forms of sexual assault, CSA remains vastly under-reported and therefore, often goes undetected. Estimates suggest that only about one-fourth of all committed offenses are reported and further substantiated (Bolen, 2001). Finkelhor and Jones (2006) attribute one cause of the apparent decline in the rates of CSA to the possibility that fewer cases are being reported and substantiated in more recent years. Many factors may affect the likelihood of CSA not being reported. Children, who might be naïve due to their lack of life experience, are less likely to recognize these behaviors as abusive (Johnson, 2004). Younger children may also lack the communication skills (Johnson, 2004) and resources (Taylor-Browne, 1997) required to report CSA. In addition, society has a tendency to "blame the victim," which may cause victims to avoid disclosure for fear of being made culpable for the act (Taylor-Browne, 1997). Professionals who fall under the "mandatory reporting" laws provided evidence that reporting has declined because of a fear of "backlash" (Finkelhor \& Jones, 2006). This "backlash" may lead to negative publicity associated with false allegations and lawsuits stemming from these false allegations (Finkelhor \& Jones, 2006). The greatest 
implication of under-reporting is the increased probability that victims will not seek out resources to help them overcome the harmful consequences often experienced by victims of CSA. It has been determined, however, that at least some of the decline seen in the number of cases of CSA is, in fact, a legitimate decline.

A legitimate decline in CSA is supported by several important findings. For example, the decline in cases that are being reported to law enforcement is paralleled by self-report data collected by the National Crime Victims Survey (NCVS; Finkelhor \& Jones, 2006). In addition, declines are mirrored in all forms of reporting sources and for all types of sexual abuse (Finkelhor \& Jones, 2006). Finally, not only have reports of child sexual abuse declined, but other related indicators of child welfare (e.g., teen suicide, running away, juvenile delinquency) have also shown a decline over the same period of time (Finkelhor \& Jones, 2006).

Consequences of child sexual abuse. The consequences of experiencing sexual abuse as a child are just as variable as the acts that constitute CSA. Child sexual abuse can affect many areas of the victim's life and may include short-term (initial) effects as well as long-term consequences. Short-term effects may include: emotional disturbance (Browne \& Finkelhor, 1986), fear (Browne \& Finkelhor, 1986), anxiety and hostility (Browne \& Finkelhor, 1986), and inappropriate sexual behavior (e.g., sexually “acting out"; Browne \& Finkelhor, 1986). Long-term effects can last well into adulthood and include: depression (Beitchman et. al.,1992; Browne \& Finkelhor, 1986; Paolucci et. al., 2001), negative effects on academic performance (Paolucci et. al., 2001), self-destructive behavior (Browne \& Finkelhor, 1986; Paolucci et. al., 2001), anxiety (Beitchman et. 
al.,1992; Browne \& Finkelhor, 1986), fear (Beitchman et. al.,1992), feelings of isolation and stigma (Browne \& Finkelhor, 1986), poor self-esteem (Browne \& Finkelhor, 1986), tendency toward revictimization (Beitchman et. al.,1992; Browne \& Finkelhor, 1986), substance abuse (Browne \& Finkelhor, 1986), posttraumatic stress disorder (Paolucci et. al., 2001; Rowan; 2006) and adult sexual dysfunction (Beitchman et. al.,1992; Paolucci et. al., 2001; Rowan, 2006). Despite these common effects, not all victims are impacted by CSA the same way, and victimization will be expressed differently across individuals, families, and communities.

Additionally, the consequences of being victimized by CSA are influenced by many factors. For example, behavioral consequences of CSA may be affected by the child's age at the onset of the abuse (Beitchman et. al.,1992; Johnson, 2004; Paolucci et. al., 2001), the child's sex (Beitchman et. al.,1992; Paolucci et. al., 2001), the child's development (Johnson, 2004), the physical acts performed during the abuse (Beitchman et. al.,1992), threats, bribes and force used during the abuse (Beitchman et. al.,1992; Johnson, 2004; Paolucci et. al., 2001), fear of retribution (Johnson, 2004), fear of culpability (Johnson, 2004), frequency and duration of the abuse (Beitchman et. al.,1992; Johnson, 2004), the child's resilience (Johnson, 2004), family functioning (Beitchman et. al.,1992) and relationship to the perpetrator (Johnson, 2004; Paolucci et. al., 2001). Therefore, although victims are impacted differentially by CSA, there is no doubt that its impact is significant.

It is clear that CSA is incredibly harmful and warrants greater attention. Child sexual abuse affects a significant number of children and may affect their successful 
transition into adulthood, as well as, their ability to live a productive, fulfilling life. As research in this area continues, the field continues to gain new knowledge and insight into how and why these abusive acts occur. In return, research has informed the development of successful prevention, intervention, and treatment programs. The goal of evidencebased programming is to begin to more effectively combat this problem.

\section{Prevention}

Current prevention efforts most often follow the public health approach to addressing CSA which emphasizes the larger community as opposed to any single individual. According to the Centers for Disease Control and Prevention (CDC; Centers for Disease Control and Prevention, 2004, p. 1), “sexual violence prevention efforts address perpetration, victimization, and bystander attitudes and behaviors, and seek to identify and enhance protective factors that impede the initiation of sexual violence in atrisk populations and in the community." Conversely, following the ecological model, sexual violence prevention makes efforts to address multiple levels of the society within which an individual resides. Individuals are not exempt from the influence of their environment; therefore, successful prevention programming should address influencing factors at the individual, interpersonal, institutional, community, and societal levels of analysis. While prevention efforts typically utilize the public health approach, strategies should also incorporate aspects of prevention that reflect person-environment interactions at different levels of the ecological model. Through the lens of community psychology, ecological theory posits that individuals and community organizations are interdependent on one another (Kelly, Ryan, Altman, \& Stelzer, 2000). Given this relationship, 
individuals have differential experiences in different ecological settings (Kelly et al, 2000). An ecological setting consists of the individual, interpersonal relationships, and the different environments within which an individual develops (e.g., institutions, geographical/social communities, attitudes and values of society; Kelly et al, 2000). Both the public health approach and the ecological model are discussed in greater detail in the following sections.

The public health approach. The public health approach to prevention focuses on the overall health of a population as opposed to any one individual (Centers for Disease Control and Prevention, 2004). Prevention programs typically focus on one of three levels, which depend on when the intervention takes place. These levels are typically referred to as: (1) Primary, (2) Secondary, and (3) Tertiary prevention.

These three levels of prevention can be discussed within the context of preventing CSA. The goal of primary prevention is to reach youth and the wider community to provide them with the necessary tools and information to avoid becoming a victim of CSA (Centers for Disease Control and Prevention, 2004). School-based prevention programs are an example of primary prevention. For example, some of these programs teach youth about the "good touch-bad touch" continuum as a mechanism to educate them about saying "no" to abusive overtures, and helps them understand what kind of behavior is and is not appropriate to engage in with others. Secondary prevention specifically targets individuals who are already at risk and intervenes before the abuse occurs (Centers for Disease Control and Prevention, 2004). Police stings to catch Internet predators are examples of secondary prevention, in which police officers pose as youth 
targets online. Once the potential offender has made arrangements to meet the youth, the police unit intervenes and makes an arrest when they have probable cause, thereby preventing the abuse from occurring. Lastly, tertiary prevention efforts take place after the abuse has occurred (Centers for Disease Control and Prevention, 2004). In the context of CSA, tertiary prevention typically involves the treatment of offenders to prevent future reoffending. In the case of CSA, tertiary services also seek to address and prevent secondary consequences of abuse (e.g., PTSD, depression) experienced by victims. Incorporating the ecological model into the public health approach fosters prevention programs that are likely to have a greater impact.

Ecological model of prevention. Prevention programs may be designed following Bronfenbrenner's (1979) ecological model, which includes multiple levels of analysis or context (e.g., family, institutions, community) as opposed to focusing solely on the target individual (e.g., potential victim, potential perpetrator, convicted offender). A modified version of Bronfenbrenner's (1979) ecological model (see Figure 1) follows that an individual develops within a multitude of systems and, therefore, his behavior is influenced by each of these systems (i.e., individual, interpersonal, institutional, community, and societal). These systems are nested within each other and are all interconnected (Renk, Liljequist, Steinberg, Bosco, \& Phares, 2002). This nesting of multiple systems within each other is especially important when considering the prevention of CSA. By definition, the victims of CSA are children. Due to their naivety and lack of life experience, children are not equipped to understand the manipulative nature of these crimes, nor should they be relied upon to protect themselves. Therefore, 
by following the ecological model in the development of prevention programs, a wider net is cast to provide adults and professionals with the knowledge and skills necessary to be more vigilant care takers. The results of the current study are intended to have utility in informing prevention programs at multiple levels of the ecological model.

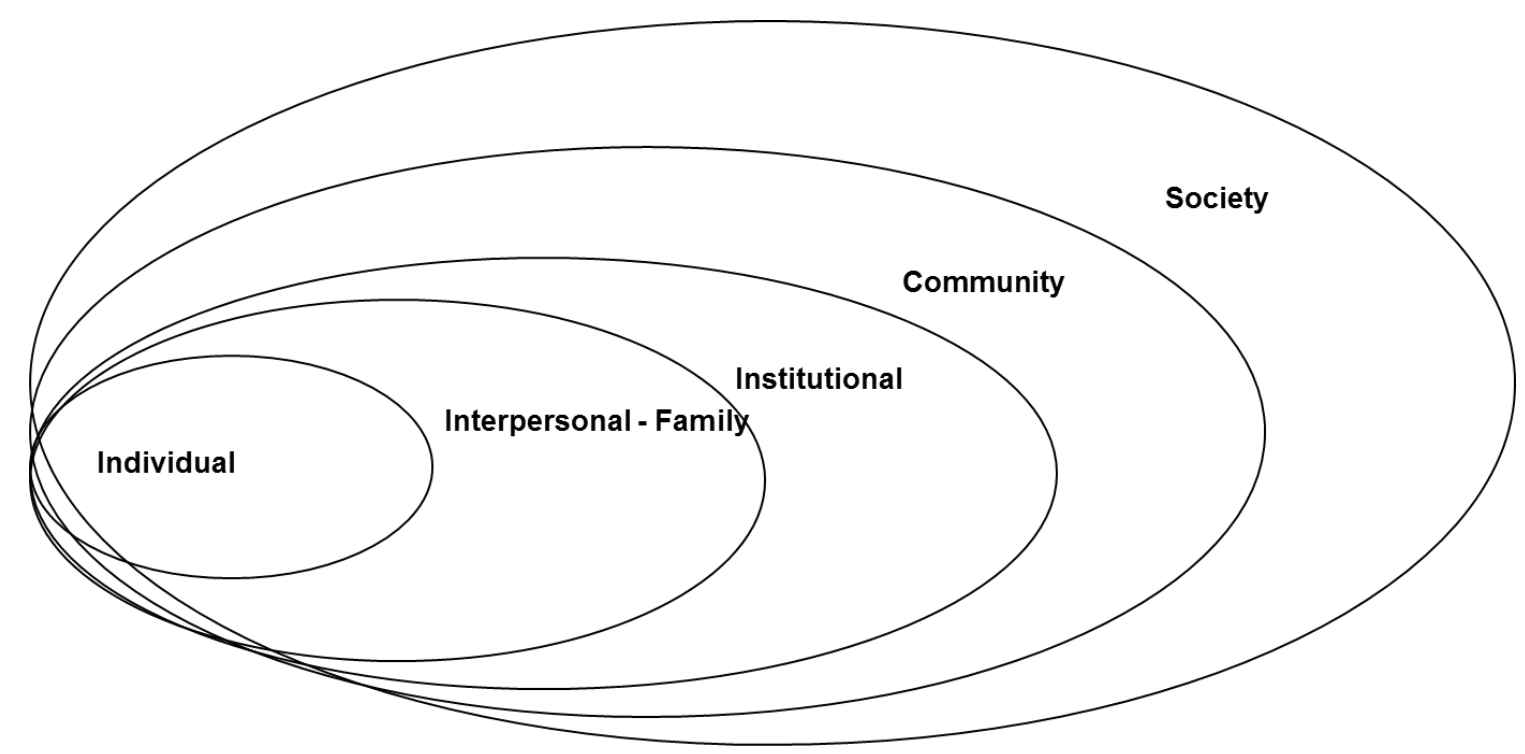

Figure 1. The Ecological Model

It is important to recognize that each of the levels of the ecological model can be targeted with the primary, secondary or tertiary prevention efforts discussed in the public health approach. In addition, targeting multiple levels of the ecological model will also increase the number of resources and individuals involved, therefore increasing the impact of prevention efforts. Finally, due to the nested nature of the levels within the ecological model, when prevention efforts are targeted at the societal level, there is a potential for the effects to "trickle" down to lower levels (e.g., a media campaign catches the attention of a principal who initiates prevents efforts at his/her school). Therefore, 
programs at the societal level have the potential for the greatest amount of impact not only at its own level, but also at all of the lower levels.

Combining the public health approach and the ecological model. As noted earlier, primary, secondary, and tertiary prevention efforts are possible at each level of the ecological model. For example, at the individual level of the ecological model (i.e., with a tertiary prevention focus), the target of a program is the offender themselves and the goals at this level are to adjust the individual's attitudes and beliefs, reduce impulsive antisocial behavior, address an abusive childhood history and any substance use concerns (Centers for Disease Control and Prevention, 2004). In contrast, a potential offender displaying "risky behaviors" (e.g., self-recognition of a sexual interest in children, spending time with younger children) may participate in counseling, therapy, and/or support groups to prevent offending behavior (i.e., secondary prevention; Jewkes, Sen, \& Garcia-Moreno, 2002). Finally, primary prevention efforts in local high schools at the individual ecological level may provide classes to teach all adolescent males about healthy dating relationships, respectful behavior toward women, and about the consequences of inappropriate or illegal sexual behaviors to avoid the development of atrisk behaviors that could lead to sexual offending (i.e., primary prevention; Orchowski, Gidycz, \& Murphy, 2010).

At the interpersonal/family level, the goal is to address detrimental relationships between the individual and others (e.g., sexually aggressive peers, physically violent family members, unsupportive family environment). For example, at the secondary prevention level, an adolescent who has been identified as having an adverse family 
environment may participate in family therapy (Jewkes, Sen, \& Garcia-Moreno, 2002). At the institutional ecological level, the prevention target is the organization that provides youth with a safe environment through support services, education, recreation and leisure activities (Kaufman, Patterson, Hayes, Tews \& Schuett, 2012). The goal of primary prevention at the institutional level may be to address problems such as inadequate supervision, "one-to-one" activities involving a youth and a supervisory staff member, and the physical layout of the organization which may have "risky" secluded areas (Kaufman, Patterson, Hayes, Tews \& Schuett, 2012). At the community ecological level, norms, values, expectations, and behaviors of the community of interest are often the focus of prevention (Kaufman, Patterson, Hayes, Tews \& Schuett, 2012). Goals at this level often aim to impact community climate, systems that work within the community, and laws and policies associated with a given community (Centers for Disease Control and Prevention, 2004). Primary prevention targets at this level may include a lack of support from the criminal justice system, an apparent lack of concern about the ramifications of sexual assault and poverty (Centers for Disease Control and Prevention, 2004). Finally, at the societal ecological level, the focus turns to macro-level factors. Macro-level factors are the societal norms and expectation and widely held beliefs that make up the broader social environment (Bronfenbrenner, 1979); such as, inequality based on gender, sexual orientation, and policies that reinforce discrimination and inequities (Centers for Disease Control and Prevention, 2004). Efforts aimed at targeting this level of the ecological model may focus on the acceptance of the sexualization of children in the media and the objectification of women (Kaufman, Patterson, Hayes, 
Tews \& Schuett, 2012). For example, a primary prevention intervention might focus on efforts to reduce major advertisers' use of images that sexualize young children and suggest this as acceptable and normative.

Current child sexual abuse prevention efforts. In addition to targeting multiple levels of the ecological model, prevention programs have also attempted to target different significant life stages throughout the course of development and focus on preventing the onset of offending behaviors. Programs of this sort look to prevent the initiation of vulnerabilities associated with the onset of offending (Smallbone, Marshall, \& Wortley, 2008). In general, developmental prevention efforts focus on four life stages: (1) Early attachment experiences; (2) Transition to school; (3) Transition to high school; and (4) Transition to parenthood (Smallbone, Marshall, \& Wortley, 2008). Within these four life stages, these programs address healthy interpersonal and intimate relationships with children, adults and peers (Smallbone, Marshall, \& Wortley, 2008).

Recently, there has been an increased interest in situational prevention approaches to CSA. Instead of exclusively targeting individuals, situational prevention focuses on what is present in the immediate behavioral and environmental setting that may facilitate the occurrence of CSA (Wortley \& Smallbone, 2006). The basis of the situational prevention approach to CSA is that many criminal activities are conducted because of opportunities and contexts that are conducive to the successful completion of a crime. Therefore, it stands to reason that reducing identifiable behavioral and environmental risks has the potential to greatly diminish the likelihood of a crime being successfully carried out in a particular setting (Kaufman, Mosher, Carter, \& Estes, 2006). This 
approach has the greatest application in non-residential, public spaces (e.g., community parks and pools) and organizations that serve children, teens, and families (e.g., Boys \& Girls Clubs, YMCA, schools, hospitals). This approach has a place in the design of new organizational settings as well as in the modification of existing programming. For example, an organization may apply the situational prevention approach when designing the layout of their new building to reduce the number of secluded spaces or to increase "line of sight" to enhance supervision.

There are also a multitude of prevention programs that directly address potential victims and their families. In general, child-focused prevention programs have received mixed support. Child focused prevention programs are most often found in schools and place an emphasis on teaching children personal safety and what to do if a child feels they have been victimized (Renk et al., 2002). On the positive side, child-focused programs do provide many benefits. Gibson and Leitenberg (2000) found that, in their sample, individuals who did not participate in a school-based sexual abuse prevention program were twice as likely to experience sexual abuse as those who did participate. Gibson and Leitenberg (2000) also addressed the concern that child-focused programs teach children that sex is bad, which may increase children's fear and anxiety about sex. In their sample, no significant differences in sexual satisfaction, participation in consensual intercourse, or the age of first consensual sexual intercourse were found between those who participated in prevention programs and those who did not. In contrast, at the foundation of these programs is the notion that offender behaviors (i.e., current and potential) cannot be changed and tend to perpetuate blaming the victim (Renk 
et al., 2002). Child-focused programs strive to teach children how to avoid becoming a victim, therefore, placing responsibility of prevention on the child (Renk et al., 2002). As a result, a child who is unsuccessful at preventing the abuse may feel responsible for his or her victimization (Renk et al., 2002). Concern has been raised regarding these programs both in terms of the potential for "victim blaming" and the logic associated with "pitting" child victims against adult and older teen offenders. Especially in the context of CSA, victims are typically much smaller in size than their offender, rarely have the physical ability to resist, typically lack the cognitive ability to understand what is happening, and may be confused about the harm associated with CSA (Johnson, 2004; Taylor-Browne, 1997). In no other context does society expect children to be responsible for their own safety (Renk et al., 2002). The responsibility to keep children safe from harm should be in the hands of their adult caretakers. Considering the mixed findings for studies of child-focused prevention programs, the inclusion of additional target populations in future research will increase our knowledge about prevention programming efforts (Renk et al., 2002).

In 2002, Renk and his colleagues published a review of the efficacy of childfocused CSA primary prevention programs. This review concluded that, although children who participated in prevention programs tended to perform better on outcome measures related to "good-touch, bad-touch" and self-assertion, it is unclear how much this increase results in applicable skills that can be used as a deterrent to offenders. In addition, it was found that children experienced substantial decay of information over the 
month following participation in the prevention program. To alleviate some of the responsibility placed on children, prevention programs have also targeted parents.

Finally, in addition to simply supporting their children through child-focused prevention programs, parents can also gain skills and knowledge of their own to assist in combating this problem (Wurtele \&Kenny, 2010). For example, educated parents are in a better position to help their children continue to gain safety skills, foster open lines of communication about CSA, and promote healthy sexuality (Wurtele \& Kenny, 2010). It has been found that many circumstances that increase the vulnerability of children to CSA are related to their home environment; parents may use information from prevention programs to create a safer home environment and limit interactions between their children and potential offenders (Wurtele \& Kenny, 2010). The involvement of parents and the efficacy of parent-focused prevention programs are unknown, yet parents have been identified as a crucial component in the successful prevention of CSA (Wurtele, 2010).

Given the complexities and hidden nature of CSA, it is critical to incorporate multiple perspectives into the development of effective prevention initiatives. Since prevention efforts in this area are designed to thwart perpetrators' abusive overtures, the offender perspective is uniquely valuable, but is often overlooked. This small literature provides a variety of insights into the types of offender behaviors and strategies that should be the target of CSA prevention programming. For example, Budin and Johnson (1989) pioneered the solicitation of convicted sexual offenders' experiences to evaluate the efficacy of current prevention programs. Offenders were also asked to provide 
suggestions about how to prevent future CSA. In this study, the offenders supported teaching children to tell if they are being abused (91.67\%), to say "no" to abusive approaches (90.28\%), "properly handle their genitalia (i.e., proper touching of their private parts by others) " $(88.89 \%)$, and to not get in a car with a stranger $(79.17 \%)$. However, the offenders indicated that current prevention approaches lacked important information that would have prevented them from carrying out their offense. For example, the offenders suggested that prevention programs targeting children should include training that encouraged children to: avoid parent's friends who are too friendly; remain in close vicinity to those they know; do not walk around the house wearing only underwear; and to hit, kick, or bite adults that engage in inappropriate touching. Convicted offenders also made suggestions for programs that target parents. They suggested that parents should be trained to provide emotional fulfillment and good supervision in organizational settings, as well as to make children feel loved and cared for and to encourage them to ask questions. An apparent theme in the suggestions offered by offenders participating in this study are related to creating a better understanding of the modus operandi or "method of operation" that offenders used in the perpetration of CSA.

Modus operandi refers to how the offender goes about committing his crime. For example, one offender (i.e., in Budin \& Johnson's [1989] study) suggested the integration of information on keeping a child in close proximity to the people he or she knows. They went on to suggest that children who are secluded from their caretakers are at greater risk to be victimized. This highlights the value of studying CSA offenders' modus operandi as 
a means of identifying common patterns of perpetration. Once recognized, common patterns of perpetration can be integrated into prevention programs to inform children, parents and/or professionals working with children regarding potentially dangerous or risky situations. The following section addresses offenders' modus operandi in greater detail and offers more specific definitions.

\section{Modus Operandi}

The most significant type of information the prevention field can gain from CSA offenders is likely to be a better understanding of their modus operandi (i.e., how their crimes were committed). Offenders' modus operandi can be placed within a temporal framework beginning with the identification of a potential victim and ending with efforts to maintain victim silence following the onset of abusive acts. Within this temporal framework, is important information regarding offenders' strategies for carrying out their abusive intents and critical clues to more effective prevention. The following sections discuss modus operandi in more detail.

Defining modus operandi. Modus operandi (MO) is a predictable "pattern of behaviors a perpetrator displays in the period prior to, during, \& following illicit sexual contact" (Kaufman et al., 1996, p. 18), or "the actions taken by an offender to perpetrate the offense successfully" (Douglas, Burgess, Burgess, \& Ressler, 1997 p. 353 as cited in LeClerc, Proulx, \& Beauregard, 2009). Kaufman, Holmberg, Orts, McCrady, Rotzien, Daleiden, \& Hilliker (1998) proposed a temporal framework that describes the MO of CSA offenders. The major categories in this framework include: the identification of a potential victim; the offender engaging in strategies that are intended to gain the victim's 
trust and/or the trust of their parents; luring the victim to go with the offender for the purpose of abuse; obtain the victim's compliance in the sexually abusive acts; and finally, maintain the victim's silence regarding the abuse. The steps leading up to the abuse is often referred to as "grooming," and the overall time taken by the offender to complete this process can vary considerably. Differences in the time from the identification of the victim to the onset of the abuse can be effected by a variety of factors including, but not limited to, the relationship between the offender and the victim, the quality of supervision provided to the victim (and sometimes the offender [e.g., with adolescent offenders]) and the availability of locations for the abuse to occur (i.e., environmental aspects; LeClerc \& Tremblay, 2007).

Grooming. The process of grooming undeniably relies on the concept of trust (Mcalinden, 2006). Trust has previously been defined as "a behaviour [sic], or attitude, which permits risk-taking behaviour [sic] (Mcalinden, 2006, p.344).” By utilizing strategies to gain the trust of not only his potential victim(s), but also their parents, the offender is intentionally working to halt suspicion and to ease the progression along the continuum of abuse (Mcalinden, 2006). One way to maintain "innocence" as an offender is to make the sexual interaction appear "normal" to the victim (LeClerc \& Tremblay, 2007). This normalization will reduce uncomfortable feelings experienced by the victim that may lead to a child either stopping the abuse or telling someone about it. To do this, the offender may present the sexually abusive act as a game, as a nurturing act, or by convincing the victim that the sexual acts are part of the maturation process (Young, 
1997). To date, there is a paucity of research literature describing the strategies that offenders use as part of the grooming process.

There is a significant gap in the literature regarding in-depth descriptions of CSA offenders' MO (Kaufman et al, 1996; Mcalinden, 2006). Further, there is a critical need to better understand the details associated with each temporal step in MO processes. A clearer identification of these patterns of behavior has significant implications for the prevention of CSA, as well as, for the treatment of CSA offenders (Kaufman et al., 1996; LeClerc, Proulx, \& Beauregard, 2009).

\section{Prevention and Modus Operandi}

Effective sexual violence prevention and intervention programs are predicated on our ability to identify and address visible risk factors that suggest an individual is "setting up" or grooming a child or teenager for sexual abuse. In fact, the purpose of research related to the $\mathrm{MO}$ of child sexual offenders has historically been to prevent future crimes of this nature (LeClerc, Proulx, \& Beauregard, 2009). Despite the critical need for MO information to guide the development of more effective prevention approaches, CSA offenders have been identified as an underutilized resource for informing CSA prevention programs (Kolko, 1988; Reppucci \& Haugaard, 1989). In part, it's likely that some researchers have been reluctant to incorporate offenders' input into the prevention planning process, questioning their motives and suggesting that their input may be unreliable. At the same time, evidence from empirical studies suggests that offenders can provide valuable information regarding their MO, particularly when measures are completed anonymously (Abel, Becker, Mittelman, Cunningham-Rathner, Rouleau, \& 
Murphy, 1987; Kaufman, Hilliker, Lathrop, Daleiden, \& Rudy, 1996; Kaufman \& Patterson, 2010).

Child sexual abuse offenders hold a wealth of insight into how these crimes are committed. In fact, offenders have access to aspects of the CSA MO process that is otherwise unavailable. Research on CSA's MO has revealed that offenders use a complex and intricate process to commit their crimes in ways that will reduce the risk of detection (Kaufman et al, 2006). Further, evidence suggests that offenders are "creatures of habit" and tend to utilize the same strategies on all of their victims, indicating detectable patterns of perpetration (Elliot, Browne, \& Kilcoyne, 1994). Finally, this process is situationally dependent and there is no "one size fits all" approach to CSA (Kaufman et al., 2006); therefore, prevention programs should be created to address the nuances in the offender-victim-environment interaction. For example, the offenders in Budin and Johnson's (1989) study indicated that prevention efforts do not place enough emphasis on abuse perpetrated by offenders who are known to the child. A greater knowledge of risk factors that facilitate the perpetration of CSA (e.g., offender age, offender-victim relationships, victim's age, victim's gender) can be used to tailor prevention programs to better address the types of abusive advances that offenders are most likely to make toward a given group of potential victims (Kaufman et al, 2006). This type of programmatic refinement offers a great deal of potential for increasing the efficacy of CSA prevention programming.

Prevention programs can benefit greatly from increasing knowledge about grooming factors that can be identified before the onset of abusive acts. One of the most 
promising areas in this continuum is how offenders lure their victim(s) (Kaufman \& Patterson, 2010). This represents one of the earliest steps in the grooming process and perhaps one with the greatest potential to prevent CSA. By identifying patterns in luring strategies, parents and professionals working with children can become vigilant caretakers and more effective interventionists because they will understand why certain behaviors feel suspicious. This study examined offender luring strategies and how these strategies may be related to CSA offenders' age and their relationship to their victim. The study's focus was based on both this dimension's (i.e., luring) potential for impacting prevention programming as well as it's fit with other MO dimensions that have previously been investigated (e.g., victim trust, gaining victim compliance, and maintaining victim silence). 


\section{Literature Review}

The following literature review will first examine the aspects of CSA offenders' MO that have previously been investigated. The literature review will then examine the existing research which has investigated differences in CSA victim selection and details of abusive acts perpetrated by CSA offenders. The review will explore this small literature within the context of two key variables: offenders' age and offender-victim relationship. Finally, a critique will be presented to identify gaps in the research literature and the discussion will highlight how this study will address these concerns.

\section{Modus Operandi of CSA Offenders}

Research focused specifically on the MO of CSA offenders began in the late 1980s and was largely exploratory and descriptive in nature (LeClerc, Proulx, \& Beauregard, 2009). As patterns began to emerge, it became clear that although specific strategies used by an offender at any given time may differ, CSA offenders do tend to follow similar processes throughout the commission of their crimes. Building upon this descriptive knowledge, the addition of the Modus Operandi Questionnaire (MOQ; Kaufman, 1994), allowed research programs to begin to identify and address gaps in the literature.

A few key patterns of perpetration emerged early in the research literature. First, the ability of CSA offenders to identify vulnerable children (e.g., child of a single parent [particularly single mothers], children who did not have a lot of friends) became evident across studies as important to victim selection (Budin \& Johnson, 1989; Conte, Wolf, \& Smith, 1989; Elliot et al., 1994). The use of desensitization (i.e., introducing the victim to 
sexual contact by beginning with non-sexual touches and slowly increasing the sexual nature of the contact) to normalize sexual contact has been found to be a strategy used by most offenders (Berliner \& Conte, 1990; Conte, Wolf, \& Smith, 1989; Elliot, Browne, \& Kilcoyne, 1994; Kaufman \& Patterson, 2010; Lang \& Frenzel, 1988; LeClerc, Proulx, \& McKibben, 2005; Smallbone \& Wortley, 2000). For example, offenders indicated that they attempted "accidental" touches of the victims' private parts or their own private parts against the victim, suggested cuddling, or initiate play wrestling (Elliot et al., 1994). Finally, a high tendency for offenders to use bribes and enticements (Budin \& Johnson, 1989; Elliot et al., 1994; LeClerc et al., 2005; Kaufman et al., 1996; Kaufman et al. 1998; Smallbone \& Wortley, 2000) as well as threats and/or coercion throughout their offense process emerged (Berliner \& Conte, 1990; Elliot et al., 1994; Kaufman et al., 1996; Kaufman et al. 1998; Lang \& Frenzel, 1988; LeClerc et al., 2005; Smallbone \& Wortley). However, in addition to common patterns, research at this early stage also uncovered a multitude of other offenders' behaviors important to the MO of CSA offenders.

Lang and Frenzel (1988) published the first study that focused specifically on this subject. Lang and Frenzel (1988) conducted interviews with 100 adult CSA offenders who had only female victims. This study found that many offenders offered to babysit their victims or would sneak into their victims' bedroom after they were asleep to initiate sexual contact. They also found that offenders often used threats and/or coercion to initiate the sexual contact (e.g., misuse of authority, threatening gestures, withholding privileges). Finally, making the child feel special also appeared as a pattern among their 
study participants (e.g., calling the victim "Daddy's Girl”, doing special favors, avoiding punishment, telling the victim they loved them).

Conte, Wolf, \& Smith (1989) conducted exploratory research in this area by interviewing 20 adult offenders. In this study, offenders were asked what they did to engage victims in sexual contact, what they said to engage victims in sexual contact, how they gained control, and if they threatened their victim. Results indicated that offenders offered material enticements and engaged potential victims in a non-sexual relationship before attempting sexual contact. Offenders talked about sex with their victims and made sexual jokes to segue their relationship in to one of a sexual nature. To gain control of their victims, they used adults' implied authority and physical presence (i.e., larger physical size) and they isolated their victim from others. Finally, offenders most often threatened that someone, whether it is the offender, the victim, or the victim's family or friends, would somehow be harmed if the victim disclosed the abuse.

Budin and Johnson (1989) were the first to investigate the MO of CSA offenders through a survey format. Seventy-two adult male CSA offenders (non-incestuous and incestuous) completed a questionnaire about their approaches, their methods of gaining cooperation, and how they prevented their victims from reporting the abuse. Nonincestuous and incestuous CSA offenders were found to be fairly similar in the strategies that they used. The most common strategies, across groups, used throughout the abuse were to act as the victim's friend and to play children's games. However, non-incestuous perpetrators offended against friends of previous victims and victims who had been offended against by one of the perpetrator's friends more often than incestuous CSA 
offenders. Of the individuals who presented their victims with gifts, non-incestuous CSA offenders endorsed this strategy more often than incestuous CSA offenders. To gain victim cooperation in the abusive acts, hitting the victim was the most common response followed by the threat of using a weapon. To prevent victim reporting of the abuse, the most common response was hitting their victim.

Elliot and her colleagues (1994) interviewed 91 adult offenders about their MO strategies and found that one in five $(20 \%)$ offenders in this sample gained the trust of the potential victim's family as part of their MO strategy. Another very interesting finding from this study was that $84 \%$ of the offenders in this sample indicated the consistent use of one of two strategies, which varied by offender depending on which strategies they believed increased the probability they would successfully commit CSA. In addition, $48 \%$ of the offenders isolated their victims by offering to babysit, either at the victim's home or in their own home. While babysitting their victims, $27 \%$ talked about sex, $20 \%$ bathed or dressed their victim, and $21 \%$ coerced the victim into believing that the abusive acts were for a different purpose (e.g., people who love each other, good for educational purposes). Other strategies used to initiate sexual contact were bribes or favors (46\%), love and affection (30\%), and creating a "teaching opportunity (53\%)." Elliot and her colleagues (1994) also asked about the first "move" they made, the first time a victim was immediately engaged in a sexual act. The most common response was genital touching and kissing (40\%), followed by asking the child to undress and/or lie down (32\%). To gain victim cooperation, $46 \%$ of participants used bribery and gift giving and $44 \%$ used coercion and persuasion. Finally, when asked how they maintained a sexual relationship 
with their victims, the most common response was that they portrayed the abuse as a game $(42 \%)$, followed by threatening dire consequences or harm $(24 \%)$, or threatening to blame the victim and ending the relationship (20\%).

Child victims of CSA have also been utilized as to gain knowledge about MO. Berliner \& Conte (1990) interviewed 23 child victims, 21 of which were offended against by an adult male and 2 of which were offended against by adolescent males. The focus of this particular study was the strategies used to gain victim cooperation and maintain victim silence. To gain cooperation, offenders told victims that they were special, were the only one who understood the offender, or confided in their victim about their adult or sexual relationships. A pattern of coercion was also identified throughout these interviews and reflected threats of physical harm to the victim, the offender, or the victim's family, and abandonment or rejection. Finally, participants stated the their offender made them feel complacent in the abusive acts by stating that the victim liked it or wanted it because "you didn't tell me to stop." They were also told that they were now more mature. These strategies made the victims feel as though it was their fault and therefore, they did not want to tell anyone about the abuse.

With the introduction of the MOQ (Kaufman, 1994), researchers now had a particular framework within which to conduct their research that was, previously, not available. In addition to creating more consistent work across studies by providing researchers with the temporal process within which these crimes are committed, definitions of grooming process components (e.g., gaining victim compliance, maintaining victim silence) became more consistent across research programs (LeClerc et 
al., 2009). Much of the research on MO, after the introduction of this questionnaire, focused on specific sections of the MOQ (Kaufman, 1994).

The most studied component of CSA offenders' MO using the MOQ has been the strategies they use to gain victim cooperation in abusive acts (Kaufman et al., 1996; Kaufman, Wallace, Johnson, \& Reeder, 1995; LeClerc, Proulx, \& McKibben, 2005; Smallbone \& Wortley, 2000; Wortley \& Smallbone, 2006). There have also been a few studies conducted to investigate strategies used to gain victim's trust (LeClerc et al., 2005; Smallbone \& Wortley, 2000) and maintaining victim's silence (LeClerc et al., 2005; Smallbone \& Wortley, 2000). Finally, Smallbone and Wortley (2000) and Wortley and Smallbone (2006) also looked at strategies use to access victims and obtain time alone with the victims.

To date, there is only one study addressing the strategies used to lure the victim for the purpose of committing CSA. Smallbone and Wortley (2000), in their sample of 182 adult offenders in Queensland, Austrailia who completed the MOQ, found that, in general, bribery was used with the greatest frequency to lure victims for the purpose of committing CSA. Force was used by only $3.6 \%$ of the offenders, $2.4 \%$ offered to show the child a weapon, and $1.8 \%$ threatened physical harm to the child. In addition, many of the more severe coercive strategies received no endorsement by participants in this sample. Although differences were not explicitly tested, extra-familial CSA offenders had a higher frequency than intra-familial CSA offenders of giving their victims alcohol ( $5.1 \%$ vs. $3.8 \%$, respectively), cigarettes ( $8.5 \%$ vs. $2.5 \%$, respectively), and drugs ( $5.1 \%$ vs. $0 \%$, respectively). Results between the two groups were mixed regarding their use of 
bribes and enticements and threats and coercion, which may be because the researchers looked at individual items and not subscale scores. In general, it appears that extrafamilial CSA offenders used strategies that fall under bribes and enticements with a greater frequency than intra-familial CSA offenders. In contrast, intra-familial CSA offenders appear to have used strategies that fall under threats and coercion with a greater frequency than extra-familial CSA offenders.

Through descriptive studies, it has been found that CSA offenders have a tendency to identify vulnerable children as potential victims, engage in a process of desensitizing their victim to sexual contact prior to committing abusive acts and engage in a variety of strategies throughout the commission of their offense (e.g., bribes and enticements, threats and coercion). Further, previous research has focused on accessing victims, gaining victim's trust, obtaining time alone with the victim, gaining victim cooperation in the abusive acts, and maintaining victim silence. One study has focused on luring strategies specifically, but it was descriptive in nature and did not explicitly test for differences among subgroups. The next section will discuss the available literature regarding differences between adolescent and adult offenders.

\section{Offender Age}

An important distinction that is often ignored in research on CSA is the difference between adolescent and adult offenders. Although previous research has identified differences on a multitude of crucial characteristics, these two groups are often not directly compared. Instead, past research on the MO of CSA offenders tends to narrow their focus to one group or the other (e.g., LeClerc, Beauregard, \& Proulx 2008; LeClerc, 
Proulx, \& McKibbon, 2005). Research has shown that adolescents are responsible for a significant number of the reported cases of sexual violence (Veneziano \& Veneziano, 2002), and the details of their crimes are vastly different from those of adults. With the presence of separate justice systems, the legal system has acknowledged that adolescents and adults are sufficiently different, but this distinction is not often a dimension attended to in research on CSA.

There is no single "profile" of a child sex offender. The most common, albeit misleading, depiction of an individual who commits a sex offense against a child is an adult male who is most likely to be characterized as a pedophile (i.e., a sexual offender with primary sexual arousal to pre-pubescent children; Finkelhor, Ormrod, \& Chaffin, 2009). However, it is important to understand that over 50\% of CSA offenders are not characterized as pedophiles (Lussier, Beauregard, \& Proulx, 2001 as cited in Michaud \& Proulx, 2001; Seto, 2009). Additionally, adolescents make up a significant portion of CSA offenders. Of the known cases brought to the attention of the criminal justice system, adolescent offenders are responsible for approximately $20 \%$ of rapes (Veneziano \& Veneziano, 2002). Adolescents also account for over one-quarter (25.8\%) of all sex offenders and more than one-third (35.6\%) of sex offenses involving juvenile victims. Approximately $5 \%$ of youth offenders are younger than 9 years old (Snyder \& Sickmund, 1999; Finkelhor, Ormrod \& Chaffin, 2009). Furthermore, it is evident that, for some adult CSA offenders, the perpetration of sexual abuse begins in adolescence (Smallbone, Marshall, \& Wortley, 2008). Adolescents are responsible for a significant number of 
CSA offences and given developmental differences between adults and adolescents, it is not surprising that the two groups may have distinctive MO.

Adolescent CSA offenders differ from adult CSA offenders on a variety of very important dimensions. For example, adolescent offenders are more likely to offend in groups. Specifically, adolescents (9.5\%) are twice as likely as adults (4.4\%) to offend in groups of three or more perpetrators (Finkelhor, Ormrod, \& Chaffin, 2009). Adolescents are also slightly more likely to offend against an acquaintance $(63.2 \%)$ compared to adults (54.8\%; Finkelhor, Ormrod, \& Chaffin, 2009). In contrast, adults are slightly more likely to offend against a family member (31.9\%) as compared to adolescents $(25.0 \%$; Finkelhor, Ormrod, \& Chaffin, 2009). When discussing victim age, adolescents are more likely to target victims under the age of $12(59 \%)$ than adult offenders (39\%; Finkelhor, Ormrod, \& Chaffin, 2009). Discrepancies in the perpetration of sexual offences committed by adolescents and adults indicate important differences in the number of offenders involved in the crime as well as typical demographic aspects of the crime. These differences, however, do not represent a comprehensive list of how these two groups act in divergent ways.

Differences in the nature of the sexual abuse perpetrated have also been found between these two groups. In an attempt to address this gap in the literature, Miranda and Corcoran (2000) explored this issue and found that adolescent CSA offenders were more likely to utilize force in the commission of their abusive acts than their adult counterparts. In addition, adult offenders were found to have engaged in vaginal, anal, or oral intercourse more often (41\%) than adolescents (13\%). In contrast, adolescents were more 
likely to engage in "digital fondling (i.e., the use of fingers in sexual activity)" more often (71\%) than adult offenders (37\%; Miranda \& Corcoran, 2000, p. 184). Research findings support important differences between adolescent and adult offenders. Given this, researchers must be cognizant of the implications of treating adolescent and adult CSA offenders as one homogenous group.

The legal system has a long standing history of treating adolescent and adult offenders as two very distinct groups. In fact, the juvenile justice system was established in response to the need to treat adults and adolescents differently within the criminal justice system (Toft \& Fellner, 2007). According to Butts and Mears (2001), in their discussion of the history of the juvenile justice system, the special status afforded adolescents within the justice system is due to recognition of differences in developmental maturity between them and their adult counterparts. These differences reflect an understanding that adolescents' continue to develop in emotional, social, and cognitive areas well into early adulthood (Steinberg, 2009). In fact, research suggests that the prefrontal cortex, the area of the brain responsible for risky decision making, is not fully developed until around the age of 25 (U.S. Department of Health \& Human Services, no date). Moreover, researchers and practitioners acknowledge that an adolescent with a criminal record will have a more difficult time transitioning into adulthood, especially when considering factors such as the effects of a criminal record on employment prospects (Steinberg, Chung, \& Little, 2004). Unfortunately, the juvenile justice system has become more punitive over time, mirroring the adult corrections system. However, over the past few decades, greater emphasis has been placed on the 
development of treatment and rehabilitation approaches tailored to the adolescent population and intended to foster the transition of youth back into the community (Kempf-Leonard, 2007; Steinberg, 2009; Steinberg et al., 2004; Toft \& Fellner, 2007).

Differences between adolescent and adult child sex offenders also manifests themselves in the groups' MO and grooming practices. For example, differential access to resources may influence the way in which CSA is perpetrated in these two groups (Kaufman et al, 1998). Adults' implied authority over children may translate into less of a need on their part to use more active strategies to groom and engage potential victims. In contrast, adolescent offenders may need to employ a broader range of grooming strategies (e.g., bribes and enticements, threats and coercion) more often to successfully commit CSA (Kaufman et al, 1998).

Kaufman and his colleagues (1998) compared and contrasted adult and adolescent CSA offenders' use of different MO strategies. Incarcerated CSA offenders completed the Modus Operandi Questionnaire (Kaufman, 1994), which asked them to report the frequency with which they used a broad variety of MO strategies as part of their offending behavior. The authors found significant group differences in the use of MO strategies. Specifically, adolescent CSA offenders used bribes and enticements to gain victim compliance, threats to involve the victim in sexually abusive acts, and tactics to maintain victim silence more often than adult CSA offenders.

\section{Offender-Victim Relationship}

As with offender age, a focus on the offender-victim relationship has also been neglected in the CSA prevention research literature (Trickett, Noll, Reifmann, \& Putnam, 
2001). For studies that have investigated this variable, the presence of a familial relationship has typically been referred to as "intra-familial," while offenders outside the family have been identified as "extra-familial."

In general, current estimates reveal that, in $90 \%$ of CSA cases, the victim is familiar with his or her offender (Snyder, 2000; Tofte \& Fellner, 2007), while other estimates suggest that between 5 and $10 \%$ of all cases of CSA involve offenders that are unknown to the victim (Gallagher, Bradford, \& Pease, 2008). When the number of cases involving offenders who were known in some way to their victim is further examined, findings indicate that in $34 \%$ of these cases the offender was a family member, while in $59 \%$, the offender was an acquaintance (Snyder, 2000). However, categorizing the offender-victim relationship is not as simple as dichotomizing relationships into these two broad categories.

Most often, studies in the literature have categorized the offender-victim relationship into two different classifications: (1) intra-familial and (2) extra-familial (Russell, 1983; Kaufman et al, 1996; Kaufman et al, 1998; Kaufman \& Patterson, 2010; Sullivan \& Beech, 2004). However, defining the offender-victim relationship as "intra-" or "extra-familial" requires more fine grain criteria. Critical to this definition is whether intra-familial is limited to blood-relations or if it includes any individual living within the same household, or some combination of the two. The most commonly used definition in the literature defines the offender-victim relationship in terms of living conditions. In other words, "intra-familial" is most often defined as offenders who are living in the same household as the victim, regardless of whether or not they are a blood-relative (e.g., step- 
father; Fischer \& McDonald, 1998; Kaufman et al, 1996; Kaufman et al, 1998; Miranda \& Corcoran, 2000; Smallbone \& Wortley, 2000). For the purpose of this study, offendervictim relationship will also be operationalized in terms of living conditions (i.e., utilizing Kaufman and his colleagues' approach, 1998). This means that intra-familial CSA applies to victims who were related to their offender(s) or living in the same household as their offender(s). In contrast, extra-familial CSA applies to victims who were not related to their offender(s) and were not living in the same household as their offender(s).

Russell (1983), found that, of those study participants who had experienced intrafamilial CSA, 40\% were victimized by either a parent (i.e. biological, step, or foster) or a sibling. Other than parents and siblings, uncles comprised the next highest proportion of intra-familial offenders (Russell, 1983). Due to the greater accessibility that intra-familial offenders have to their victims and what is typically a more intimate relationship, intrafamilial abuse has a tendency to persist over a longer period of time and result in more serious consequences for the victim and their family (Finkelhor, 1994; Fischer \& McDonald, 1998). Victims of intra-familial CSA are also more often female than male and are, on average, younger than extra-familial victims (Fischer \& McDonald, 1998; Smallbone \& Wortley, 2000).

Extra-familial CSA offenders are most often acquaintances of their victims (Snyder, 2000). For example, extra-familial offenders may take the forms of neighbors, parents' significant others, household employees, and friends of the family (Russell, 1983). The definition of extra-familial CSA offenders (i.e., not related to and not living 
with the victim) can be further extrapolated to include coaches, day care providers (Kelly, Brant, \& Waterman, 1994), teachers, sibling's friends, peers and strangers. Kelley and her colleagues (1994) also found that many perpetrators of child sexual abuse are often staff other than the "teachers" (e.g. bus drivers, janitors, family members of staff) and therefore may not be familiar by name to parents. It should be remembered that many people other than organizational employees often have access to the children. In fact, many of the incidences of extra-familial CSA occur in the youth-serving organizations that parents trust to keep their children safe (e.g., sports and recreation, day care, organizations such as Big Brothers and Big Sisters and Boys \& Girls Clubs of America; Kaufman, Tews, Schuett, \& Kaufman, 2012). Sexual offenders may seek out employment within youth-serving organizations to gain access their potential victims. These positions give the offender a position of trust, making the process of building a relationship with the victim more natural (LeClerc, Proulx, \& McKibben, 2005).

Research on differences in MO strategies between intra- and extra-familial offenders has uncovered a number of interesting distinctions. Specifically, Kaufman and his colleagues (1996) found that intra-familial CSA offenders used bribes and enticements to gain victim trust and compliance and threats or coercion to maintain victim silence more often than extra-familial CSA offenders in a sample comprised solely of adolescent CSA offenders. In a second study, Kaufman and his colleagues (1998) found that extra-familial CSA offenders used alcohol and drugs to gain victim compliance in sexually abusive acts more often than intra-familial CSA offenders in a sample comprised of both adolescent and adult CSA offenders. They also found that 
intra-familial CSA offenders used bribes and enticements to gain victim compliance in sexually abusive acts more often than extra-familial CSA offenders. Differences found in the strategies used by intra-familial and extra-familial offenders to gain victim trust, gain victim compliance, and maintain victim silence following the onset of the sexual abuse suggest that there may be important differences in CSA offenders' MO dimensions (e.g., luring) that have yet to be investigated.

\section{Critique of the Current Literature}

As made evident in the previous review, there are multiple gaps in the current research literature on the MO of CSA offenders. First, although research has differentiated offenders based on offender age and offender-victim relationship, there is a paucity of research differentiating these groups on their MO strategies. The limited research that has explored differences between these groups MO strategies, has only focused on phases of the MO process that involve gaining trust, gaining compliance in the abusive act and maintaining victim silence. In addition, the only study to date (i.e., Smallbone \& Wortley, 2000) on luring strategies used by CSA offenders, investigated the general use of these strategies and did not test differences among subgroups. This leaves

important questions regarding the relationship between MO and offender subgroups (i.e., offender age and offender-victim relationship) unanswered.

Only three studies investigating MO strategies have been completed since 2000 (i.e., LeClerc et al., 2005; Smallbone \& Wortley, 2000; Wortley \& Smallbone, 2006). Much of the research literature on MO dates back to the 90s and late 80s. Data collected for this study was collected in the early to mid-2000s. As a result, it represents a more 
current reflection of offenders' MO behaviors. As society develops, it is important that research remain current.

Further, research involving the MO of CSA offenders has tended to be based on fairly small sample sizes. It has not been uncommon for study sample sizes to be between 20 and 25 participants (i.e., Berliner \& Conte, 1990; Conte et al., 1989; LeClerc et al., 2005). Only five studies have utilized sample sizes over 100 (i.e., Kaufman et al., 1996; Kaufman et al., 1995; Lang \& Frenzel, 1988; Smallbone \&Wortley, 2000; Wortley \& Smallbone, 2006). Smaller sample sizes tend to limit the generalizability of findings due to being less representative of the population. The current study utilized information from over 700 CSA offenders to address this concern.

Kaufman and his colleagues (1996) found that the utilization of questionnaires over structured interviews resulted in offender respondents providing greater details regarding their MO. It has been suggested that the anonymity of a questionnaire increases offenders' sense of confidentiality. Even so, many research studies in this area have utilized an interview format when soliciting information from offenders (i.e., Berliner \& Conte, 1990, Conte et al., 1989; Lang \& Frenzel, 1988; Elliot, Browne, \& Kilcoyne, 1994). The proposed study will utilize the MOQ (Kaufman, 1994) with data collected in an anonymous fashion.

Building upon the previous research, which has indicated that there are subgroup differences on the dimensions of offender age and offender-victim relationship, the present study explored MO in the framework of the rational choice theory (RCT). Each of these offender characteristics (i.e., offender age and offender-victim relationship) may 
have significant implications for the types of strategies that these offenders choose to employ in the commission of their crimes. RCT suggests that the ability to carry out each crime is contingent upon the offender making decisions about their MO strategies (Cornish \& Clarke, 2002). These decisions are made to select the strategies that the offender believes will result in the successful completion of their crimes (Cornish and Clarke, 2002). A discussion of the RCT will follow to provide insight into how these decisions are motivated and how this decision making process can affect the outcome of an intended crime.

\section{Rational Choice Theory}

Rational choice theory began as a theory in economics and is based on the relationship between a behavior and the severity of the corresponding sanctions for engaging in that behavior (Clarke \& Cornish, 1985). It follows that all individuals make decisions based on a cost-benefit analysis of outcomes related to engaging in a variety of different behaviors that could be responsive to a particular situation. Pratt (2008) suggests that the more adverse the sanction, the less likely an individual is to engage in the behavior that warrants that sanction. As the theory has evolved, additions and revisions have been made to take into account nuances that can affect decision-making in different contexts (Pratt, 2008). According to the theory, decision-making is affected by a variety of factors. These decisions can be constrained by the time available to make a decision, the cognitive abilities of the person making the decision, and the availability of relevant information related to the decision (Cornish \& Clarke, 1986). As many different disciplines (e.g., psychology, sociology, criminology, economics, law) began to agree 
that offenders were fairly rational decision makers, Cornish \& Clark (1986) began applying the rational choice approach to criminology.

In the context of offending, RCT posits that offenders commit their crime(s) in such a way as to maximize benefits and minimize costs. From a criminology standpoint, offenders act to maximize beneficial outcomes such as sexual gratification, dominance, or financial gain, depending on the particular crime and the offender (LeClerc, Beauregard, \& Proulx, 2008). Concurrently, they act to minimize the probability that they will be apprehended by the authorities. Therefore, the commission of a crime is assumed to be calculated and planned before the offender actually engages in the offending behavior (Clarke \& Cornish, 1985). Factors that impact these decisions include victim attributes, situational cues, and offender modus operandi (LeClerc \& Tremblay, 2007). Applying RCT to criminal behavior requires that a fundamental distinction be made between criminal involvement and criminal events (Cornish \& Clarke, 1986). Criminal involvement refers to the processes by which an offender decides to be involved in a criminal act, to continue throughout the criminal act, and to end the criminal act (Cornish \& Clark, 1986). Most often, decisions regarding criminal involvement are multistage and each stage may be influenced by different factors (Cornish \& Clarke, 1986). In contrast, decisions regarding a criminal event involve minimal processes and relate to immediate contexts (Cornish \& Clarke, 1986). These characteristics of criminal involvement, according to RCT, fall directly in line with the temporal framework of CSA MO proposed by Kaufman and his colleagues (1998; 2010). Again, this framework describes the progression of an offender identifying and accessing a potential victim 
through their sexual abuse of the victim, and efforts to maintain victim silence following the offense (Kaufman et al, 1998; 2010).

During each of the progressive phases involved in the MO framework (Kaufman et al., 1998; 2010), the offender must make a decision that will successfully set up the next step in the process. As an illustrative example and drawing from the results found by Kaufman and his colleagues $(1996 ; 1998)$, an offender who has identified his live in girlfriend's daughter as a potential victim, must employ strategies to gain her trust. Knowing that his girlfriend is a "strict" parent, he begins to give the potential victim special privileges (e.g., staying up past her bedtime; having ice cream during the day). By choosing things that he knows his potential victim wants, he is intending to gain her trust and to segue into the luring phase. These decisions will be affected by situational factors (e.g., supervision) and may be different for each potential victim. Through the process of weighing his options (and possible consequences), the offender selects "grooming" strategies to maximize his victims eventual compliance in sexually abusive acts and minimize potential consequences (e.g., being thrown out of his girlfriend's house, arrest, incarceration). At each step in the process, careful attention is paid to risks and benefits with an eye toward accomplishing his goal of CSA, while limiting the probability that he will be caught and turned in to the authorities. Applying the RCT to CSA implies that the offenders' MO is consciously constructed. Strategies are chosen by the offender based on experiences that suggest to him which specific strategies are more likely to lead to the successful completion of the sexually abusive act(s) (LeClerc \& Tremblay, 2007). Moreover, it seems likely that CSA offender subgroups of interest in this study (i.e., 
based on offender age and offender-victim relationship, will have a differential impact on the resources and situational factors that offenders have available to them when making decisions at the various stages of the MO continuum (i.e., identifying victim, accessing victim, gaining trust, luring victim, gaining compliance, and maintaining silence). Rational choice theory will help frame this investigation's research questions as well as contribute to the interpretation of study findings.

\section{Purpose of the Present Study}

The purpose of this study was to explore potential differences in luring strategies related to CSA perpetrator subgroups based on offender age and offender-victim relationship. There is a paucity of systematic research investigating the strategies used to lure the victim for the purpose of abuse. By expanding on the research previously done by Kaufman and his colleagues $(1996 ; 1998)$, the research community can gain further insight into the MO of different subgroups of CSA offenders. The following section provides structure for the current study based on the existing literature. Where the literature provides guidance, hypotheses were proposed. In areas that are more exploratory, research questions were proposed. 


\section{Research Questions and Hypotheses}

\section{The Use of Bribes and Enticements}

Research Question 1: Do subgroups of CSA offenders (i.e., [a] adult and adolescent and [b] intra- and extra-familial) differ in the frequency with which they use bribes and enticements to lure their victim for the purpose of committing CSA?

First, this study investigates whether there are differences between adolescent and adult CSA offenders in the frequency of their use of bribes and enticements to lure their victim(s) for the purpose of committing CSA. Previous research has found that offender age has a significant effect on MO strategies such that adolescent CSA offenders employed various strategies (e.g., bribes and enticements. more often than adult CSA offenders (Kaufman et al, 1998). It has been suggested that adolescents' lack of authority and potential lack of size differential between the offender and the victim may require that adolescents use more manipulative strategies to engage their victims and establish sexual control (Kaufman et all, 1998). In addition, adolescents' assumed lack of income may result in their use of non-monetary (e.g., privileges) or low cost (e.g., giving candy) bribes and enticements which may not be very potent (i.e., last very long) and increase the need for more frequent use of MO strategies (Kaufman et al, 1998). The present study seeks to expand on the current body of knowledge by investigating the use of these strategies during the CSA luring phase of the MO process. Accordingly, a pattern of findings consistent with adolescents' greater use of MO strategies in the existing literature is expected for this study's findings regarding the use of luring strategies. 
Hypothesis $1 \mathrm{a}(\mathrm{Hla})$ : It is hypothesized that adolescent CSA offenders will use bribes and enticements to lure their victim(s) more often than adult CSA offenders.

The second area of investigation seeks to differentiate between intra- and extrafamilial CSA offenders with regard to their use of bribes and enticements to lure their victims for the purpose of committing CSA. Previous research suggests that the offendervictim relationship is significantly related to MO strategies such that intra-familial CSA offenders employed bribes and enticements and threats and coercion with greater frequency than extra-familial CSA offenders to gain victim trust and compliance and to involve them in the abusive act (Kaufman et al, 1996; Kaufman et al., 1998).

In contrast, Smallbone \& Wortley (2000) found that extra-familial CSA offenders utilized bribes and enticements to lure victims with a greater frequency than intra-familial CSA offenders. This finding by Smallbone \& Wortley (2000) regarding bribes and enticements contradicts findings by Kaufman and his colleagues (1996; 1998); however, Kaufman and colleagues $(1996 ; 1998)$ did not investigate luring specifically. It is plausible that the inverse relationship is true during this phase of the grooming process. For example, due to less intimate relationships between extra-familial CSA offenders and their victims, as compared to intra-familial CSA offenders and their victims', extrafamilial CSA offenders may need to provide their victims with bribes and enticements to convince their victims to go with them. Therefore, the descriptive findings by Smallbone \& Wortley (2000) will be used to inform the hypothesis related differences between intraand extra-familial offenders' use of bribes and enticements to lure the victim for the purpose of committing CSA. 
Hypothesis $1 b(H 1 b)$ : It is hypothesized that extra-familial CSA offenders will use bribes and enticements to lure their victim(s) more often than intra-familial CSA offenders.

\section{The Use of Threats and Coercion}

Research Question 2: Do subgroups of CSA offenders (i.e., [a] adult and adolescent and [b] intra- and extra-familial) differ in the frequency with which they use threats and coercion to lure their victim for the purpose of committing CSA?

Secondly, this study investigates whether there are differences between adolescent and adult CSA offenders in the frequency of their use of threats and coercion to lure their victim(s) for the purpose of committing CSA. As discussed in the previous section, research has found that adolescents' utilize manipulative strategies with a greater frequency than adults across the MO continuum (Kaufman et al., 19998). Adolescents' increased use of threats and coercion may be the result of their inability to keep their victims engaged throughout the course of the grooming process and/or the sexual abusive acts through what appear to be more positive means (e.g., giving them candy; Kaufman et al, 1998). The present study seeks to expand on the current body of knowledge by investigating the use of these strategies during the CSA luring phase of the MO process. Accordingly, a pattern of findings consistent with adolescents' greater use of MO strategies in the existing literature is expected for this study's findings regarding the use of luring strategies.

Hypothesis $2 a(\mathrm{H} 2 \mathrm{a})$ : It is hypothesized that adolescent CSA offenders will use threats and coercion to lure their victim(s) more often than adult CSA offenders. 
In support of the finding by Kaufman and colleagues (1996; 1998), Smallbone \& Wortley (2000) also found that intra-familial CSA offenders utilized threats and coercion to lure victims with a greater frequency than extra-familial CSA offenders. The established, often more intimate, relationship between the offender and the victim of intra-familial CSA may give threats and coercive statements increased credibility (Kaufman et al, 1996; 1998). Accordingly, a similar pattern of findings, consistent with existing literature, is expected for this study's findings regarding the use of luring strategies.

Hypothesis $2 b(H 2 b)$ : It is hypothesized that intra-familial CSA offenders will use threats and coercion to lure their victim(s) more often than extra-familial CSA offenders.

\section{The Use of Drugs and Alcohol}

Research Question 3: Do subgroups of CSA offenders (i.e., [a] adult and adolescent and [b] intra- and extra-familial) differ in the frequency with which they use drugs and alcohol to lure their victim for the purpose of committing CSA?

Third, this study investigates whether there are differences between adolescent and adult CSA offenders in the frequency of their use of drugs and alcohol to lure their victim(s) for the purpose of committing CSA. The present study will be the first to compare adolescent and adult CSA offenders on their frequency of the use of drugs and alcohol to lure their victim(s) for the purpose of committing CSA. Previous research has found that there is a linear relationship in the frequency of the use of drugs and alcohol as victim age increase (Kaufman et al., 1996). Additionally, previous research has found differences in the use of drugs and alcohol by different offender-victim relationships (i.e., 
Kaufman et al., 1998; Smallbone \& Wortley, 2000), but the differences in adolescent and adult offenders use of this strategy has yet to be investigated at any point on the MO continuum. For the purpose of exploring potential differences between these groups (i.e., adolescent and adult CSA offenders), there is no predicted direction.

Hypothesis $3 a(H 3 a)^{* 2}$ : It is hypothesized that adolescent and adults CSA offender differ in the frequency of their use of drugs and alcohol to lure their victim(s) for the purpose of committing CSA?

Previous research has found that extra-familial CSA offenders utilize drugs and alcohol more frequently than intra-familial offenders to gain victim compliance (Kaufman et al, 1998). Extra-familial offenders may be more tempted to utilize drugs and alcohol for their sedative effect on their victims, reducing resistance; whereas, intrafamilial offenders may be less likely to utilize drugs and alcohol due to the fear that it may increase the possibility of detection (Kaufman et al, 1998; Kafuman \& Patterson, 2010). The present study looks to expand on the current knowledge by investigating the use of these strategies during the luring phase of the MO of a CSA offender. Accordingly, a similar trend is expected with the current data.

Hypothesis $3 b(H 3 b)$ : It is hypothesized that extra-familial CSA offenders will use drugs and alcohol to lure their victim(s) more often than intra-familial CSA offenders.

\section{Potential Moderating Effects of Offender Age and Offender-Victim Relationship}

Research Question 4: Does offender-victim relationship moderate the effects of offender age on luring strategies to lure their victim for the purpose of committing CSA?

\footnotetext{
$2 *$ indicates that the hypothesis is not guided by literature and is meant to be exploratory in nature
} 
Finally, prior to the present study, the potential that the two dimensions of interest (i.e., offender age and offender-victim relationship) have a moderating relationship on strategies to lure victims has not been investigated. Drawing from previous research conducted at other stages of the MO continuum and from previous descriptive findings regarding luring strategies used, two hypotheses and one research question were investigated. A significant moderating effect has previously been found on offenders' use of pornography to gain victim compliance, such that, offender-victim relationship had a stronger effect on adolescent's use of the strategy than on adult's use of the strategy (Kaufman, 1998). Following this finding and previous research investigating group differences in the use of strategies, the following hypotheses were investigated:

Hypothesis $4 a(\mathrm{H} 4 \mathrm{a})$ : Offender victim relationship will moderate the relationship between offender age and the use of bribes and enticements to lure the victim; such that, adolescent, extra-familial offenders will use this strategy with the greatest frequency.

Hypothesis $4 b(H 4 b)$ : Offender victim relationship will moderate the relationship between offender age and the use of threats and coercion to lure the victim; such that, adolescent, intra-familial offenders will use this strategy with the greatest frequency.

In addition, the due to the lack of previous research conducted investigating differences of the use of drugs and alcohol by adolescent and adult offenders, the following hypothesis was investigated with no predicted direction: 
Hypothesis $4 c(\mathrm{H} 4 \mathrm{c}) *^{3}$ : Offender-victim relationship will moderate the relationship between offender age and the use of drugs and alcohol to lure the victim.

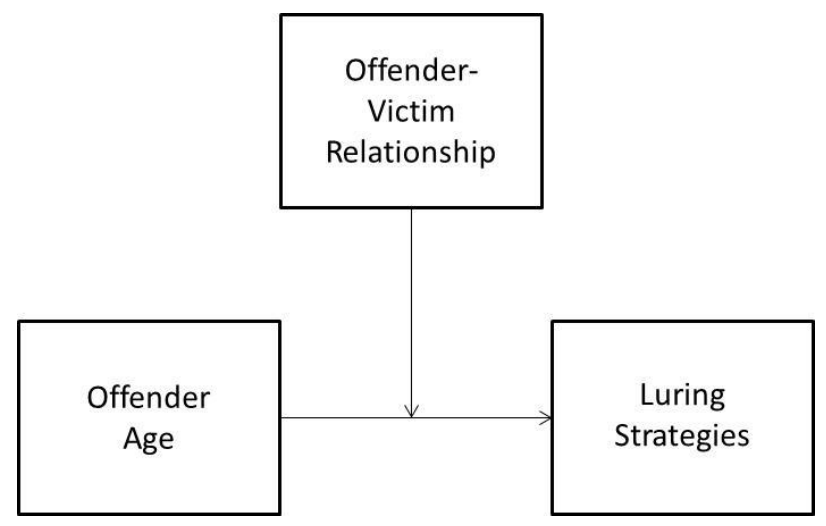

Figure 2. Moderation Model (Hypotheses 3a and 3b).

$3 *$ indicates that the hypothesis is not guided by literature and is meant to be exploratory in nature 


\section{Method}

\section{Participants}

This study is part of a larger, ongoing investigation conducted by Dr. Keith Kaufman and his colleagues. The larger project was designed to investigate offender and victim supervision and patterns of perpetration (i.e., modus operandi) of adolescent and adult CSA offenders across three ethnic/cultural groups (Supported by CDC Grant R49/CCR016517-01). The CDC funded study, included adolescent and adult CSA

offenders as well as caregivers of adolescent CSA offenders and caregivers of victims as clinical groups and a number of control groups (e.g., adolescents with no offense history, caregivers of adolescents with no offense history, adolescent non-sex offenders, caregivers of adolescent non-sex offenders, adults with no offense history, and caregivers of children who have not been victimized).

Participants for this study include a subsample of 854 identified CSA offenders recruited from correctional facilities and outpatient treatment programs in nine different states (Oregon, Washington, Texas, South Carolina, New York, Florida, Ohio, Connecticut, and New Jersey). The adult offender sample had an average age of 40.43 $(S D=11.82)$ and the adolescent offender sample had an average age of $16.77(S D=2.27)$ at the time the participants completed the set of questionnaires.

The combined sample contained a fairly even number of intra- and extra-familial CSA offenders, with $56 \%$ having an intra-familial victim who was related to them or lived in the same home and $44 \%$ having an extra-familial victim who was not related to them and did not lived in the same home. Participants were considered to be an 
adolescent CSA offender if they committed their offense before their 18th birthday and they were considered to be an adult CSA offender if they committed their offense after their 18th birthday. Cell sizes for each subgroup (i.e., adolescent/intra-familial, adolescent/extra-familial, adult/intra-familial, adult/extra-familial) can be found in Table 1. A chi-square goodness of fit statistic was calculated to examine if the cell sizes were equal across groups. This test indicates that subgroup cell sizes are significantly different $\chi^{2}(3, \mathrm{n}=728)=28.945, p<.001$.

\section{Design}

The current study utilized a cross-sectional, non-experimental design. All questionnaires were completed at the same time within each facility, and each participant completed only one questionnaire. This study investigated the relationship between offender characteristics (i.e., the age of the offender and the nature of the offender-victim relationship) and the strategies most often used by the offender to lure their victim(s) for the purpose of committing CSA.

\section{Descriptions and Measurement of Study Constructs}

Offender age. Offender age was dichotomized for the purpose of the present study. This is consistent with the current legal definition for adolescent and adult offenders as well as with previous research (Kaufman et al, 1996; Kaufman et al, 1998; Miranda \& Corcoran, 2000). More specifically, the present study will dichotomize offenders' by age, considering offenders who committed CSA prior to the age of 18 as an adolescent and offenders who committed CSA at or later than the age of 18 as adults. Offender age was determined based on one continuous, self-report item on the 
Demographics Questionnaire (Kaufman, 2001) which asked, "Your age when you first sexually abused that person." This question is in reference to the last child that the offender sexually abused.

Offender-victim relationship. For the purpose of this study, offender-victim relationship was operationalized in terms of living conditions, following the criteria used by Kaufman and his colleagues (1998). This means that intra-familial CSA applies to victims who were related to their offenders or living in the offenders' household. In contrast, extra-familial CSA applies to victims who were not related to their offenders and not living in the offenders household. Offender-victim relationship was determined based on one self-report item at the start of the Modus Operandi Questionnaire (Kaufman, 1994) that asked respondents to indicate, "If you lived with or were related to the children you abused, please check here." If participants checked that particular box, they were considered an intra-familial CSA offender for the purposes of this study. Conversely, if they did not check that box, they were treated as an extra-familial CSA offender.

Modus operandi. The dependent variables of interest in the present study relate to the MO of the offenders. The Modus Operandi Questionnaire (MOQ) was used to gather data for the larger study (Kaufman, 1994). This 339-item self-report questionnaire was developed using feedback from offenders, victims, and professionals (i.e., law enforcement, offender treatment, victim treatment) in relevant fields (Kaufman et al., 1998). The questionnaire asked each participant to identify the frequency with which he used each of the strategies listed in the commission of CSA. The questionnaire asked 
each participant to report on each of the time points that represent the CSA MO continuum discussed and included the following sections: (1) Where You Found and Had Time Alone with Children You Abused; (2) How You Gained the Trust of the Children You Abused; (3) About the Time Before the Sexual Abuse Began; (4) Questions About the Sexual Abuse; (5) Ways of Getting the Children you Sexually Abused Involved in Sexual Activity; (6) Threats to Get the Children you Sexually Abused Involved in Sexual Activity; (7) Keeping the Children Quiet About the Sexual Abuse.

Of concern to this study is part of the first section of the questionnaire, which asks offenders to identify the frequency with which they used various strategies to lure their victim for the purpose of committing CSA. Participants were asked to indicate the frequency of which they used a number strategies in response to the question, "How often did you use the following ways to get the children you sexually abused to go with you to the place where you had sexual contact with them?" Exploratory factor analysis in a sample of 350 adolescent sexual offenders yielded three different subscales within this section describing strategies used to lure the victim to the abuse site: (1) "Bribes and Enticements;" (2) “Threats and Coercion;" and (3) "Drugs and Alcohol” (see Table 2; Kaufman et al., 1996). The "Bribes and Enticements" subscale was composed of ten items. Example items from this subscale include: "Having a pet that they wanted to see or play with" and "Telling them that you were going to do something fun." The "Threats and Coercion" subscale was made up of twenty items and included items such as: "Letting them see you angry or violent with another person" and "Saying that you would hurt one of their family members if they did not come along." The "Drugs and Alcohol" 
subscale contained three items. An example item from this subscale is: "Giving them alcohol." All questions were answered using a 4-point Likert-type scale from 0 (Never) to 3 (Almost Always) describing the frequency with which they used each strategy.

The MO dependent variables were created by calculating subscale scores for each participant. A mean composite subscale score was computed for each participant on each of three subscales (i.e., bribes and enticements, threats and coercion, and drugs and alcohol). To compute these composite scores, responses to each of the items were averaged for each of the subscales. Each participant, therefore, had three scores ranging from 0 to 3, with higher scores indicating greater frequency of use of the strategy represented by the corresponding subscale.

The "Luring Victims" section of the questionnaire was the focus of this study and has yet to be used in systematic research. However, other subscales contained within these questionnaires have reliability coefficients between .73 and .93 indicating moderate to strong reliability.

\section{Procedure}

Participants were identified from within their respective correctional facilities as CSA offenders and given the opportunity to participate in this study. Adult offenders completed an informed consent form ensuring anonymity and confidentiality. Facility representatives have legal custody of adolescent offenders; therefore, facility directors provided consent for adolescent offenders. Adolescent participants also provided assent to participate through an assent form that was read aloud to them. All responses were anonymous and participation was voluntary. Potential participants were screened for 
reading ability, comprehension, and significant mental disabilities. Once participants were screened and provided their consent, they were given paper and pencil questionnaires that were all completed in the same sitting. This set of questionnaires included the Demographic Questionnaire (Kaufman, 2001) and the Modus Operandi Questionnaire (Kaufman, 1994). In addition, participants completed the Supervision Questionnaire (Kaufman, 2001). The information collected from the Supervision Questionnaire will not be included in this study. Participants took approximately 40 minutes on average to complete the MOQ. Upon completion, a research assistant checked the measures to ensure that items had not been missed, collected each of the packets, and returned them to Portland State University, where they remain secured in a locked file cabinet behind two other locked doors. 


\section{Results}

\section{Exclusion Criteria}

Prior to analyses being conducted, exclusion criteria were applied to the sample population. Female participants or those who did not indicate their sex $(n=11)$ were not included in analyses. In addition, participants who indicated that they had committed CSA as both an adolescent and an adult $(n=76)$ were excluded from analyses. Finally, participants who completed their questionnaires in Spanish $(n=39)$ were excluded from the study to eliminate the possibility that the meaning of items as intended in English did not translate accurately into Spanish. Finally, five participants from the adolescent sample and four participants from the adult sample were identified as outliers due to their age and were removed from further analyses.

Removing all participants meeting exclusion criteria resulted in a final sample size of 728. The sample was comprised of participants that self-identified as White $(\mathrm{n}=$ 405, 55.6\%), Black $(n=97,13.3 \%)$, Latino $(n=93,12.8 \%)$, American Indian $(n=18$, $2.5 \%)$, Asian $(\mathrm{n}=8,1.1 \%)$, and mixed participants $(\mathrm{n}=107,14.7 \%)$. Three hundred and sixty-eight participants were characterized as adolescent CSA offenders with an average age of $13.43(S D=2.01)$ at the time of their last offense and 360 were characterized as adult CSA offenders with an average age of $33.80(S D=10.28)$ at the time of their last offense.

\section{Preliminary Analyses}

Prior to conducting inferential analyses, a series of preliminary analyses were conducted to test the normality of the variables of interest and the assumptions of the 
general linear model. Tests of skew and kurtosis revealed that the dependent variables for this study differed significantly from normal, such that the data had a strong positive skew. A series of transformations were considered in an attempt to correct non-normality. However, the transformations did not significantly correct the skew. Since transformations make the interpretation of results difficult and they did not correct nonnormality, data remained untransformed for analyses. The general linear model is robust to non-normal data, especially with a large sample size, when non normality is due to skew and not outliers, which was the case for this data.

Additionally, a series of statistical tests were run to determine the inclusion of the proposed covariates. Two one-way ANOVA analyses were run to test the relation between potential categorical covariates and all three dependent variables. Significant differences in the state the data was collected in were found on the bribes and enticements subscale, $F(8,716)=5.466, p<.001$, such that participants in New Jersey indicated the highest use $(M=.839, S D=.700)$ of bribes and enticements, followed by Washington $(M=.803, S D=.669)$, Oregon $(M=.803, S D=.629)$, Ohio $(M=.794, S D=$ $.668)$, Texas $(M=.748, S D=.574)$, Connecticut $(M=.550, S D=.640)$, Florida $(M=$ $.548, S D=.630)$, New York $(M=.491, S D=.541)$, and finally, South Carolina $(M=$ $.265, S D=.415)$. Differences were also found on the threats and coercion scale, $F(8,716)$ $=5.463, p<.001$, such that participants in Oregon indicated the highest use $(M=.356$, $S D=.474)$ of threats and coercion, followed by Florida $(M=.226, S D=.419$, Ohio $(M=$ $.224, S D=.283)$, Washington $(M=.205, S D=.357)$, Connecticut $(M=.200, S D=.400)$, New Jersey $(M=.170, S D=.213)$, Texas $(M=.143, S D=.321)$, New York $(M=.142$, 
$S D=.249)$, and finally, South Carolina $(M=.083, S D=.266)$. Differences were not found on the drugs and alcohol scale, $F(8,716)=1.650, p=.107$. No significant differences were found relative to ethnicity on the bribes and enticements scale, $F(8,719)$ $=1.612, p=.118$, the threats and coercion scale, $F(8,719)=.779, p=.622$, or the drugs and alcohol scale, $F(8,719)=.891, p=.523$. Based on these results, the state the data was collected in was retained as a covariate, but ethnicity was not included in further analyses.

To test the relationship between potential continuous covariates and the three dependent variables, a series of regression analyses were run. The number of months participants had been in sex specific treatment was significantly related to the bribes and enticements scale, $(\beta=.149, t(3)=3.991, p<.001)$ and the threats and coercion scale, $(\beta$ $=.146, t(3)=3.946, p<.001)$, but not the drugs and alcohol scale, $(\beta=-.069, t(3)=-$ $1.773, p=.077)$. The participant's total number of victims was significantly related to the bribes and enticements scale, $(\beta=.219, t(3)=5.835, p<.001)$ and the threats and coercion scale, $(\beta=.251, t(3)=6.747, p<.001)$, but not the drugs and alcohol scale, $(\beta=$ $.028, t(3)=.726, p=.468)$. Finally, victim age was not significantly related to the bribes and enticements scale, $(\beta=-.056, t(3)=-1.524, p=.128)$ or the threats and coercion scale, $(\beta=.-.051, t(3)=-1.398, p=.163)$, but it was significantly related to the drugs and alcohol scale, $(\beta=.114, t(3)=2.988, p<.01)$. Based on these results, all three potential covariates were retained for further analyses.

Finally, to examine the reliability of the subscales proposed as dependent variables, Chronbach's alpha coefficients were calculated using the final sample. The 
bribes and enticements subscale had a Chronbach's alpha of .82. The threats and coercion subscale had a Chronbach's alpha of .89. Based on the value of these coefficients, the bribes and enticements and threats and coercion subscales indicate sufficient reliability. Finally, the drugs and alcohol subscale had a Chronbach's alpha of .68. There is a direct relationship between reliability and the number of items that comprise the subscale. Therefore, due to the drugs and alcohol subscale being only a three item scale, a Chronbach's alpha of .68 was deemed to be acceptable for this project with the understanding that significant results should be interpreted with caution. The reliability of the drugs and alcohol scale is discussed further in the discussion section.

\section{Inferential Analyses}

Prior to hypothesis testing, two independent sample $t$-tests were conducted to investigate group differences (i.e., offender age and offender-victim relationship) on the three subscales (i.e., drugs and alcohol, bribes and enticements, and threats and coercion) prior to controlling for covariates. Significant group differences in offender age were found such that adolescent CSA offenders utilized threats and coercion with a greater frequency $(M=.30, S D=.45)$ than adult CSA offenders $(M=.17, S D=.26)$, where equal variances were not assumed, $t(589.79)=4.73, p<.001$. However, no significant differences were found in offender age for their use of drugs and alcohol $t(726)=.11, p=$ .92 , or their use of bribes and enticements $t(726)=1.05, p=.29$. When investigating group differences in offender-victim relationship, a significant difference was found in intra-familial and extra-familial CSA offenders use of drugs and alcohol, where equal variances were not assumed, $t(582.23)=2.03, p=.04$. Specifically, extra-familial 
offenders utilized drugs and alcohol with a greater frequency $(M=.12, S D=.38)$ than intra-familial CSA offenders $(M=.07, S D=.29)$. However, no significant differences were found in offender-victim relationship for their use of bribes and enticements, $t(726)$ $=-1.01, p=.31$, or their use of threats and coercion $t(726)=-1.15, p=.25$.

A 2 X 2 MANCOVA was conducted to test proposed hypotheses. Independent variables included offender age with two levels - adolescents $(n=343)$ and adults $(n=$ $337)$ - and offender-victim relationship, also with two levels - intra-familial $(\mathrm{n}=386)$ and extra-familial $(\mathrm{n}=294)$. Following results of preliminary analyses, four covariates (i.e., state of data collection, number of victims, victim age, and number of months participating in sex specific treatment) were included in the analysis to control for their effects on the dependent variables. Participant race was tested and found to have no significant effect on the dependent variables; therefore, it was removed from further analyses. The three subscales (i.e., drugs and alcohol, bribes and enticements, and threats and coercion) that comprise the luring strategies scale were included as dependent variables.

Hypothesis la (H1a): Adolescent CSA offenders will use bribes and enticements with a greater frequency than adult CSA offenders.

The main effect of offender age was not found to be significant, $F(1,673)=.193$, $p=.660$, partial $-\dot{\eta}^{2}=.000$. The means and standard deviations for each group are available in Table 3. 
Hypothesis $1 b$ (H1b): Extra-familial CSA offenders will use bribes and enticements to lure their victim(s) with a greater frequency than intra-familial CSA offenders.

The main effect of offender-victim relationship was not found to be significant, $F(1,673)=3.644, p=.057$, partial $-\dot{\eta}^{2}=.005$. The means and standard deviations for each group are available in Table 3.

Hypothesis 2a (H2a): Adolescent CSA offenders will use threats and coercion with a greater frequency than adult CSA offenders.

The main effect of offender age was found to be significant, $F(1,673)=3.859, p$ $<.050$, partial $-\dot{\eta}^{2}=.006$. As seen in Figure 3, adolescents, on average, used threats and coercion with a significantly greater frequency $(M=.271, S E=.022)$ than adults $(M=$ $.202, S E=.022)$.

Hypothesis $2 b(H 2 b)$ : Intra-familial CSA offenders will use threats and coercion to lure their victim(s) with a greater frequency than extra-familial CSA offenders.

The main effect of offender-victim relationship was found to be significant, $F(1$, $673)=5.549, p<.05$, partial $-\dot{\eta}^{2}=.008$. Intra-familial offenders, on average, used threats and coercion with a significantly greater frequency $(M=.269, S E=.018)$ than extrafamilial offenders $(M=.203, S E=.021)$.

Hypothesis $3 a\left(\mathrm{H}_{3} \mathrm{a}^{*{ }^{4}}\right.$ : It is hypothesized that adolescent and adults CSA offender differ in the frequency of their use of drugs and alcohol to lure their victim(s) for the purpose of committing CSA?

\footnotetext{
$4 *$ indicates that the hypothesis is not guided by literature and is meant to be exploratory in nature
} 
The main effect of offender age was not found to be significant, $F(1,673)=.065$, $p=.799$, partial $-\dot{\eta}^{2}=.000$. The means and standard deviations for each group are available in Table 3.

Hypothesis 3b (H3b): Extra-familial CSA offenders will use drugs and alcohol to lure their victim(s) with a greater frequency than intra-familial CSA offenders.

The main effect of offender-victim relationship was not found to be significant, $F(1,673)=1.628, p=.202$, partial $-\dot{\eta}^{2}=.002$. The means and standard deviations for each group are available in Table 3.

To test the potential moderating relationship between offender age and offendervictim relationship, a second 2X2 MANCOVA was conducted. Independent variables, dependent variables, and covariates were the same as the first MANCOVA. However, in this second MANCOVA, an interaction term was created to test hypotheses 4a-c.

Hypothesis 4a (H4a): It is hypothesized that adolescent and adults CSA offender differ in the frequency of their use of drugs and alcohol to lure their victim(s) for the purpose of committing CSA?

A significant moderating relationship between offender age and offender-victim relationship was not found, $F(1,672)=.506, p=.477$, partial $-\dot{\eta}^{2}=.001$. The relationship between age and the use of bribes and enticements did not depend on offender-victim relationship. This is can be seen in the means and standard deviations for each group (see Table 3). 
Hypothesis $4 b$ (H4b): Offender victim relationship will moderate the relationship between offender age and the use of threats and coercion to lure the victim; such that, adolescent, intra-familial offenders will use this strategy with the greatest frequency.

A significant moderating relationship between offender age and offender-victim relationship was not found significant, $F(1,672)=.094, p=.760$, partial $-\dot{\eta}^{2}=.000$. The relation between age and the use of threats and coercion did not depend on offendervictim relationship. This is can be seen in the means and standard deviations for each group (see Table 3).

Hypothesis $4 c(\mathrm{H} 4 \mathrm{c}) *^{5}$ : Offender-victim relationship will moderate the relationship between offender age and the use of drugs and alcohol to lure the victim.

A significant moderating relationship between offender age and offender-victim relationship was not found significant, $F(1,672)=.014, p=.904$, partial $-\dot{\eta}^{2}=.000$. The relation between age and the use of drugs and alcohol did not depend on offender-victim relationship. This is can be seen in the means and standard deviations for each group (see Table 3).

\section{Follow Up Analyses}

It was noted that many of the items that comprised the subscales utilized as dependent variables had extremely low base rates of responses indicating that a high number of offenders had not used that strategy as part of his MO. Due to the possibility that these items may have had significant effects on the means of these subscale scores, such that they were very low, a series of $t$-tests were run to investigate group differences at the item level. A series of transformations were attempted to correct the skew of the

\footnotetext{
$5 *$ indicates that the hypothesis is not guided by literature and is meant to be exploratory in nature
} 
dependent variables. However, these transformations did not significantly correct normality and so analyses were run without transformation. To protect against increased Type I error, $t$-tests were limited only to those items in which at least $15 \%$ of the respondents in both groups (e.g., adolescents and adults) indicated that they had used that strategy. This criterion resulted in a total of 27 independent samples $t$-tests (see Tables 4 and 5 for a list of items). After applying a Bonferroni correction to adjust the significance level to account for a larger number of tests, a significance level of .002 was used as the criterion for significance.

As can be seen in Table 6, significant differences between adolescent and adult offenders were found in three items on the threats and coercion scale (i.e., "tell them [the victim] you won't spend time with them if they don't go", "tell them [the victim] they would get in trouble if they didn't go", and "threaten to end rewards or privileges") and one item on the bribes and enticements scale (i.e., "give them [the victim] money"). Consistent with the results found in the MANCOVA analyses adolescents, on average, told their victim that they would not spend time with them if they did not go $(M=.572$, $S D=.935)$ with a greater frequency than adults $(M=.297, S D=.749)$. Adolescents, on average, told their victim that $\mathrm{s} / \mathrm{he}$ would get in trouble if s/he did not go $(M=.526, S D=$ $.926)$ with a greater frequency than adults $(M=.292, S D=.762)$. Adolescents, on average, also threatened to end rewards and privileges $(M=.723, S D=1.059)$ with a greater frequency than adults $(M=.492, S D=.938)$. However, adults, on average, gave their victim money $(M=.819, S D=1.116)$ with a greater frequency than adolescents $(M$ $=.550, S D=.968)$. 
As presented in Table 7, it can be seen that a significant difference in offendervictim relationship was found in one item on the bribes and enticements scale (i.e., "telling them [the victim] they'd get special rewards or privileges") and one item on the threats and coercion scale (i.e., "threaten with ending of privileges or rewards"). Once again, consistent with the results from the MANCOVA analysis, intra-familial offenders, on average, told their victim they would receive special rewards or privileges $(M=1.298$, $S D=1.275)$ with a greater frequency than extra-familial offenders $(M=.927, S D=$ 1.194). Additionally, intra-familial offenders, on average, threatened that they would take away special rewards or privileges $(M=.710, S D=1.066)$ with a greater frequency than extra-familial offenders $(M=.478, S D=.911)$.

Follow-up item level analyses were not conducted on any of the items that comprise the drugs and alcohol subscale due to the fact that each item was endorsed by less than $9 \%$ of participants in each group indicating that they had used that strategy. 


\section{Discussion}

The purpose of this study was to investigate the differential use of strategies to lure a victim to the abuse site by subgroups of CSA offenders (i.e., offender age and offender-victim relationship). Specifically, this study investigated the frequency with which CSA offenders of different ages and relationships to their victim utilized bribes and enticements, threats and coercion, and drugs and alcohol to lure their victim for the purpose of committing CSA. The data supported the hypothesis that adolescent CSA offenders would utilize threats and coercion with a greater frequency than adult CSA offenders (i.e., H1b). Additionally, the data supported the hypothesis that intra-familial CSA offenders would utilize threats and coercion with a greater frequency that extrafamilial CSA offenders (i.e., H2b). The data did not support the hypothesis referencing the differential use of bribes and enticements (i.e., H1a) based on offender age, such that, no significant differences were found. Finally, hypotheses relative to the differential use of bribes and enticements (i.e., H2a) and drugs and alcohol (i.e., Hypothesis 2c) based on offender-victim relationship were also not supported, such that, no significant differences were found.

This study also sought to explore differences in adolescent and adult CSA offenders regarding the frequency of their use of drugs and alcohol (i.e., RQ1) to lure their victims for the purpose of committing CSA. A significant difference between these two groups was not found.

Finally, this study investigated a potential moderating relationship between offender age and offender victim relationship. The data did not support the hypotheses 
that offender-victim relationship would moderate the relationship between offender age and bribes and enticements (i.e., H3a) or threats and coercion (i.e., H3b). In an attempt to explore the relationship between offender subgroups' use of drugs and alcohol (i.e., RQ2), no significant moderation effects were found.

\section{The Use of Bribes and Enticements}

The first research hypothesis, that adolescent CSA offenders would use bribes and enticements with a greater frequency than adult CSA offenders (i.e., H1a) was not supported. Investigation of individual items (i.e., strategies) from the bribes and enticements subscale indicated one significant group difference related to age. It was found that adult CSA offenders gave their victims money with a significantly greater frequency than adolescent CSA offenders. These results are in contrast to previous research that has found that adolescent CSA offenders tended to utilize bribes and enticements with a greater frequency than adult CSA offenders (Kaufman et al., 1998; Smallbone \& Wortley, 2000). It has previously been suggested that adolescents may engage in more bribes and enticements as strategies throughout the MO process because they lack the inherent authority and physical size that adults have (Kaufman et al., 1998). However, due to the greater likelihood that adult offenders are employed, adults are more likely to have an income and the ability to bribe their victims with money. It is possible that this finding is not necessarily reflective of bribes and enticements in general, rather it is specific to this one particular strategy.

The second research hypothesis, that extra-familial CSA offenders would use bribes and enticements (i.e., H2b) was not supported, such that no significant differences 
were revealed. Investigation of individual items (i.e., strategies) from the bribes and enticements subscale indicated one significant group difference between intra- and extrafamilial CSA offenders. It was found, in contrast to anticipated results, that intra-familial CSA offenders told their victim they would receive special rewards or privileges with a greater frequency than extra-familial offenders. Previous research conducted by Smallbone and Wortley (2000) found that a greater percentage of extra-familial offenders used various bribes and enticements to lure their victim than intra-familial, although no statistical test was run on this relationship. However, this finding supports previous work by Kaufman and colleagues $(1996 ; 1998)$ that concluded that intra-familial CSA offenders are more likely to use bribes and enticements than extra-familial CSA offenders. In the context of the particular item on which a difference was found (i.e., "tell them they would receive special rewards or privileges"), it follows that an intra-familial CSA offender may be seen as being in more of a position to provide rewards or privileges without appearing to be playing favorites and remaining less suspicious. For example, a father is more capable of allowing his son have ice cream before bed than a school teacher because of living conditions. The stronger relationship that exists between intrafamilial CSA offenders and their victims may increase the trust the victim has that the offender will follow through with their offer or rewards or privileges (Kaufman, 1998).

One explanation for the lack of significance found in the differential use of bribes and enticements as a subscale is the incredibly low base rate of multiple items. Out of the ten items, that comprised this scale, three of the items (i.e., strategies) were endorsed by less than $18.5 \%$ of the participants in each group. With $30 \%$ of the items having such a 
low base rate, it is possible, that these items impacted the overall subscale mean.

Variability in the item responses decreases drastically with such low base rates, making it more difficult to detect differences. A second explanation for the lack of significant findings could be that there is no difference between these two groups in their use of these strategies. As indicated by an effect size of .000 for bribes and enticements, the apparent lack of an effect may indicate that these strategies are common to all CSA offenders and are not used with a greater frequency by either group.

\section{The Use of Threats and Coercion}

The use of threats and coercion throughout the MO continuum emerged as a common pattern in the early research conducted on how CSA offenders commit these crimes (Berliner \& Conte, 1990; Elliot et al., 1994; Kaufman et al., 1996; Kaufman et al. 1998; Lang \& Frenzel, 1988; LeClerc et al., 2005; Smallbone \& Wortley). The third research hypothesis, that adolescent CSA offenders would use threats and coercion with a greater frequency than adult CSA offenders (i.e. H2a) was supported by study data. This finding is consistent with previous research (Kaufman et al., 1998; Smallbone \& Wortley, 2000, 2000), suggesting that adolescents engage in a higher frequency of threats and coercion because they lack the inherent authority and physical size of adults (Kaufman, 1998). Further, investigation of the items that comprise the threats and coercion subscale revealed three items (i.e., strategies) that were used differentially by the two groups. Adolescents more often: Told their victims that they would not spend time with them if they did not go along with them; That they (i.e., the victim) would get in trouble if they did not go along with them; and Threatened to stop providing privileges and rewards to 
their victims. Adolescents' greater propensity to engage in these coercive behaviors may be due, in part, to the power of peer influences in their lives. For example, Jaccard, Blanton, and Dodge (2005) found that adolescents were more likely to engage in risk behaviors (i.e., drinking alcohol and engaging in sexual activity) when peers that they were close to also manifested similar behaviors. For some adolescent offenders, it is also possible that they themselves had a similar experience as part of their own victimization. In other words, when bribes and enticements failed to motivate them to go along with their own offender, more coercive strategies were employed to ensure that the abuse came to fruition. This knowledge may lead some adolescent offenders to repeat this pattern of escalation. Future studies should investigate the possibility of this type of modeling having an impact on adolescents' use of coercive strategies (Abel, Osborn, \& Twigg, 1993).

The fourth research hypothesis, that intra-familial CSA offenders would use threats and coercion with a greater frequency than extra-familial (i.e., H2b) CSA offenders was supported by this data. This finding is consistent with previous research (Kaufman et al., 1996;1998; Smallbone \& Wortley, 2000), suggesting that intra-familial CSA offenders engage in threats and coercion with greater frequency because the threats and coercive statements are much more credible when coming from an offender within the family or the same household. Further investigation of the items that comprise the threats and coercion subscale revealed one item (i.e., strategies) that was used differentially by the two groups. Intra-familial offenders, on average, threatened to take 
away special rewards or privileges if the victim did not go with them with a greater frequency than extra-familial offenders.

\section{The Use of Drugs and Alcohol}

The fifth research hypothesis, that extra-familial CSA offenders would use drugs and alcohol (i.e., H3b) with a greater frequency than intra-familial CSA offenders was not supported. Further, the first research question, exploring potential differences in adolescents' and adult's use of drugs and alcohol (i.e., H3a*) did not reveal any significant differences.

One explanation for the lack of significance found in the differential use of drugs and alcohol is the low base rate of multiple items in this subscale. The drugs and alcohol scale only has three items. On each of these three items, less than $10 \%$ of participants endorsed the use of these strategies. In fact, two of the items were endorsed by less $6 \%$ in each study group. Given that variability in item responses decreases drastically with such low base rates, it would have been quite difficult to detect differences in this sample.

Previous research has found significant differences in the use of drugs and alcohol only between intra- and extra-familial offenders to gain victim compliance. Kaufman and his colleagues (1998) found that extra-familial adolescent offenders utilized drugs and alcohol with a greater frequency than intra-familial offenders for the purpose of gaining victim compliance in sexually abusive acts. When considering the act of luring, however, it is important to keep in mind that moving the victim is an inherent part of the definition for this step in the grooming process. In fact, a big part of the luring process is intended to remove the potential victim from a public or high traffic area to a more secluded 
location to decrease the potential for detection. Given this, the potential sedative effects of alcohol (and many drugs, as well) may actually impede the process of luring, such that it would become more difficult to move the potential victim to a location where abuse can occur. It is more plausible that drugs and alcohol would be used to gain victim compliance since their sedative effects may reduce victim resistance leading up to and during the sexually abusive act. Such a rationale may explain the small effect size found in this study, which may indicate that these subgroups of offenders do not differ in their use of drugs and alcohol to lure the victim because it is not a common strategy.

\section{Potential Moderating Effects of Offender Age and Offender-Victim Relationship}

The tenth and eleventh research hypotheses, which suggested that the offendervictim relationship would moderate the association between offender age and the use of bribes and enticements (i.e., H4a) and threats coercion (i.e., H4b), respectively, were not supported. The final hypothesis, which proposed that the offender-victim relationship would moderate the association between offender age and the use of drugs and alcohol (i.e., $\mathrm{H} 4 \mathrm{c}^{*}$ ), also did not result in a significant relationship.

It's quite likely that the very low endorsement rate for the drugs and alcohol scale items may have also adversely impacted attempts to identify the moderating effects of the offender-victim relationship and the offenders' age. At the same time, the lack of findings with regard to the bribes and enticements scale suggests that these strategies may be more universally available for use by offenders as part of the luring process. It is also possible that this scale is not sensitive enough to identify subtler differences in the use of this class of strategies that may, in fact, reflect a moderating effect of these variables. For example, 
while the "bribes and enticements" scale assesses strategies that include "giving money" or "extra privileges," it does not track the amount of money or the types of privileges that are part of this process. When considered in this way, it may be that a difference in levels or types of each strategy is actually driving the difference as opposed to the use of the overall strategy. For example, the difference may be found in the type of rewards or privileges that subgroups of offenders vary, but that they to tend to use bribes and enticements, in general, with a similar frequency. This same ideology can also be applied to potentially explain the lack of a moderating effect in the use of threats and coercion.

\section{General Discussion}

The purpose of this research was to identify common patterns among offenders. Yet, findings suggest that a number of the subscale items could more aptly be considered uncommon strategies. In support of descriptive findings by Smallbone \& Wortley (2000), many of the more severe strategies were endorsed at a very low rate. For example, all three items on the drugs and alcohol subscale were endorsed by less than $10 \%$ of the participants in this study. Pending further investigation into the process of luring, it may be necessary to return to the items included in each subscale and consider their utility as a luring strategy. When over $85 \%$ of participants are indicating that they did not use a certain strategy, it is clear that these items have minimal utility and may contribute little to the field's better understanding of offenders' MO or the types of clinical treatment needs required by CSA offenders, specifically in the context of luring strategies. These findings indicate the need to consider dropping these low endorsement items from this subscale and considering the inclusion of other items that may help foster our 
understanding of luring approaches. That being said, there is good reason to retain these items as part of the scale, as potential strategies used during other MO processes, since they represent seriously invasive grooming practices that may have important treatment implications. For example, the drug and alcohol and more coercive threats and force items may reflect the presence of more pervasive cognitive distortions, a greater amount of offense planning and a higher degree of pathology (Abel et al., 1993). The presence of these factors may require different treatment approaches for success in contrast with offenders who do not engage in behaviors of this nature.

A brief discussion is warranted regarding the practical versus statistical significance of this study. Effect sizes for the MANCOVA analyses ranged from .000 to .008 , all of which are very close, if not equal to, to 0 . Due to these low effect sizes, significant differences may be indicative of having a large sample size (i.e., $\mathrm{N}=854$ ) and not real differences in these subgroups' use of various luring strategies. It is with extreme hesitation that it is suggested that there are no real differences. This study was the first to investigate differences in the use of luring strategies; therefore, this topic begs further exploration. First, as indicated by previous research on the MO of CSA offenders, manipulation is a crucial component to the successful completion of the abusive act(s). Therefore, any information gained regarding this particular process of the MO continuum may be helpful, as it informs one more opportunity to thwart an offender's efforts.

Second, certain response patterns may have affected the data. An offender who had four victims, but used a different strategy to lure each victim may indicate that he used each of those strategies "almost never", while an offender who had one victim may indicate using 
the strategy that was used with that victim "almost always". It may be helpful to adjust the way that this process (i.e., luring) is operationalized and measured.

Looking at the response patterns of the items that comprise the luring scale, it appears that there may be alternate ways of scaling these items that may be more beneficial. For example, currently, responses are measured on a 4-point Likert-type scale from 0 (Never) to 3 (Almost Always). Response patterns indicate that many of the items were not endorsed (i.e., indicated that they had never used that strategy) by a majority of the participants, leaving little variation in the higher three points of the scale (i.e., 1 [Almost Never], 2 [Sometimes], and 3 [Almost Always]). An alternative to this 4-point Likert-type scale in conditions like this would be to dichotomize responses into "Never Used Strategy" and "Used Strategy". This would give a clearer picture of the strategies that are being used, in general. This dichotomization would provide a clear picture of the most common strategies, which may act as "red flags" to watch for. However, with the dichotomization, the responses are no longer pseudo-continuous. Therefore, the concept of the frequency of the use of these strategies is lost. Dichotomization would also limit the types of analyses that can be run; therefore limiting the types of research questions that can be addressed with the data. Finally, the items that are not endorsed by the majority of participants may have differential utility for treatment and research. These items, therefore, must be properly handled in accordance with the context that they are being used. For example, items that are, primarily, not endorsed may have little utility in research because they do not offer any new information and it may be appropriate to drop these items from the scale for the purpose of research. However, as discussed above, 
endorsement of more invasive, forceful strategies by an individual may indicate the need for more individualized treatment (Abel et al., 1993).

In addition to how responses are measured, the items that comprise the scale itself may need to revisited. It would appear that this scale is not capturing the strategies that are used the most often to lure victims for the purpose of committing CSA due to the low endorsement on so many items. One way to address this issue would be to add a qualitative component to the survey for each of the three sections (i.e., bribes and enticements, threats and coercion, and drugs and alcohol). This component could be in the form of a fill in the blank that gives the participant the ability to list a strategy they used, that was not already included on the scale. If it is found that many participants are indicating that they had used a strategy (or some version of this strategy), this may indicate that the strategy needs to be added to the scale. Additionally, this scale may need to be updated. The scale was originally developed in the mid-90's and involved gaining insight from law enforcement, offenders, victim advocates, and treatment providers. Updating the scale would require repeating this development process. However, with almost 20 years having gone by since the original development, it may be necessary to ensuring that as society has continued to develop, the scales that are being used in research are paralleling this development.

It was discussed in the preliminary analysis section, that the reliability of the drugs and alcohol subscale was lower than .70 (i.e., the cutoff for acceptable reliability in research. To further investigate the psychometric properties of this small subscale, the Spearman-Brown Prophecy Formula was utilized to predict the increase in reliability if 
the length of the subscale were to increase (Remmers \& Adkins, 1942). To closely match the length of the bribes and enticements scale, this formula was calculated with the addition of six more items. According to the Spearman-Brown Prophecy Formula, increasing this subscale from three items to nine items (i.e., three times its current length) would result in a Chronbach's Alpha of .86, indicating good reliability. One caveat of this formula is that added items must have similar psychometric properties to the items already included in the subscale. Some suggested items to increase the length of the scale and reliability, would be: the division of "drugs" into stimulants and sedatives, further differentiating drugs into legal (e.g., prescriptions) and illegal drugs (e.g., ecstasy), or listing specific types of "common" drugs (e.g., marijuana).

It is also important to consider that luring may be a context specific construct. The questionnaire asks the offender to indicate the frequency with which they employed each of the strategies to get their victim to go with them to the place where they eventually abused them. Depending on where the abusive act took place, this conceptualization of luring may not be appropriate. For example, previous research has shown that many offenders gain access to their victims by offering to babysit, whether it is in the victim's home or the offender's home (Elliot et al., 1994). In this situation, since the victim was not removed from the initial location and taken to a second location, the offender may conclude that they did not lure the child to the place where the abuse occurred. In cases of this nature, the location of the abusive acts becomes a variable of significant interest. Understanding more about these situations is an important complement to studying luring strategies and will be discussed further in the Future Directions section, which follows. 
Interestingly, in the preliminary analysis, before controlling for selected covariates, $t$-test analyses revealed a significant group difference between intra- and extra-familial CSA offenders regarding their use of drugs and alcohol. This finding was such that extra-familial CSA offenders utilized drugs and alcohol with a greater frequency than intra-familial CSA offenders. However, after controlling for selected covariates, this relationship was no longer significant. These findings may be due to one, or more, of the selected covariates affecting the two groups differentially, indicating an interaction between the covariate(s) and the independent variable. Therefore, when those covariates are controlled for, the influence of this differential impact is removed from analysis and the significance of the difference between groups is impacted. Future research should further investigate the impacts of specific covariates as key variables for analysis.

From a criminology standpoint, rational choice theory (RCT) posits that offenders will act in ways to maximize beneficial outcomes such as sexual gratification, dominance, or financial gain, depending on the particular crime and the offender (LeClerc, Beauregard, \& Proulx, 2008). In the context of the present study, the beneficial outcome is the successful luring of a potential victim for the purpose of committing CSA. Leclerc \& Tremblay (2007) suggest that offenders will engage in strategies that, based on his experience, will be the most likely to result in the luring of a potential victim. In support of RCT, findings support that distinct subgroups of offenders will draw from differential resources when engaging in the use of threats and coercion to lure their 
victim. These findings also imply that CSA offenders are not a homogenous population and that predictable patterns can be found in how these crimes are committed.

\section{Limitations}

The proposed study has a few important limitations. First, it is possible that study participants may have been at-risk for participant fatigue. The questionnaire that

contained the scale used for this study (MOQ) was part of a 339-item self-report measure. The MOQ was also only one of a series of questionnaires that the participants completed during a single session that lasted, on average, two hours. It must be considered that the participants may have become either bored or tired of filling out the questionnaire. Lack of sustained attention could have affected the data, particularly if participant did not respond to items thoughtfully. At the same time, it should be noted that participation was a novel event for participants, all participants were given a snack as part of the process approximately half way through the data collection, and participants were allowed to take a break, if needed. In addition to the standard methodological limitations common to psychological research, working with a specialized population introduces additional challenges to research. Gaining access to participants who have committed criminal offenses is difficult due to the security that surrounds them. Additionally, this research asked these offenders to reveal specific details about crimes that they have committed.

It is also important to note that the data used in this study is retrospective, selfreport data from convicted CSA offenders. This could be problematic for a couple of reasons. Due to the retrospective nature of the questionnaire, it was assumed that the participants could reliably recall the details of their past offense. Some of the participants 
were incarcerated for many years at the time that they completed study measures, and memory degradation may have impacted their reports. Further, the MOQ asks offenders to divulge very sensitive information about their offense, and some of this information may not be known to the criminal justice systems. Offenders may also be apprehensive about divulging certain details of how they commit their crimes. These details may be seen as embarrassing or may cast the offender in a much more negative light (e.g., clarifying the highly planned nature of their criminal behavior). In addition, CSA is a difficult topic to discuss with any one and this becomes an even greater concern when the offenders are divulging details of their previous offenses. Participants may withhold certain information due to the fear that they will endure additional consequences or penalties if they provide information that has yet to be reported (Abel et al., 1987). At the same time, participants were informed that the data collection process was anonymous in nature and none of the questionnaires asked for identifying information.

Additionally, the participant sample used in this study consisted solely of offenders who had been apprehended and detained. Since all of the participants had been apprehended, there is a possibility that those offenders, who have not been identified, apprehended, or convicted have a significantly different MO (e.g., more developed), one that has helped them elude detection. This restriction in sampling may attenuate the types of MO strategies reported in the available data set. Moreover, generalizability of this study's findings may be limited given the possibility that apprehended CSA offenders are not an adequate representation of the larger population of all CSA offenders. 
The data used for the present study was collected in eleven different states; however, information pertaining to potential systematic differences by state was unavailable in this data set. It is likely that there are differences in how cases are pled down; especially for adolescent CSA offenders (e.g., from sexual related charges to nonsexual related charges). Information regarding plea bargains was not available and thus was not assessed in this study. At the same time, it is possible that there may be differences across states in how cases are charged and sentenced. This may be problematic both in terms of individuals who may be included in some states as a "sex offender" despite the relatively benign nature of their offense as well as offenders who should have been included as a "sex offenders" except for the presence of more lenient plea bargaining practices in their particular state. While it is impossible to gauge the extent to which this phenomenon has affected the sample, it should be kept in mind while interpreting study findings.

It was possible to create "pure" participant groups based on offender age, such that offenders who had committed CSA both as adults and as adolescents were identifiable and removed from analyses. However, it was not possible to create "pure" participant groups based on the offender-victim relationship. Offender-victim relationship was operationalized based on the participant's response to the prompt, "If you lived with or were related to the children you abused, please check here." It is not possible, based on this prompt to identify offenders who had both intra-familial and extra-familial victims. These "mixed" offenders may have a distinguishable MO from participants in either intra-, extra-familial offenders, or both. 
Finally, it is important to consider the comprehensiveness of the scales used in the Modus Operandi measure. The 'Bribes and Enticements Used to Lure the Victim to Abuse Site' subscale consisted of only 10 items, the 'Threats and Coercion Used to Lure the Victim to Abuse Site' subscale consisted of only 20 items, and the 'Alcohol and Drugs to Lure the Victim to Abuse Site' subscale consisted of only 3 items. A reasonable conclusion based on this information is that there are additional ways in which to lure a victim that may have not been captured. Therefore, the possibility remains that a strategy used by some of the participants was not assessed. This may also limit the variability in responses, which would impact the ability to detect differences in luring tactics between the different subgroups of offenders. At the same time, the MO measure has been used in a number of studies and the luring subscales have been identified in multiple factor analyses across these studies.

\section{Implications}

The current study has implications for prevention, policy, and offender treatment. Increased knowledge about the ways in which CSA crimes are committed, can be translated into more effective programming and safer communities. Study findings could also offer findings that facilitate the tailoring of programs and policies for different types of youth serving organizations. Finally, the present study has implications for offender assessment and treatment. Each of these implications is described in more detail in the section below.

Current prevention efforts can benefit from the knowledge gained regarding the MO of CSA offenders (Kolko, 1988; Reppucci \& Haugaard, 1989). More specifically, 
information about the luring strategies used by CSA offenders may be particularly helpful since this process occurs prior to the onset of abuse (Kaufman \& Patterson, 2010). In an effort to shift the responsibility of avoiding victimization from children to parents (Renk et al., 2002), prevention programs can use study findings to inform adults in the community and professionals working with youth and families about behavioral patterns that may denote luring strategies used during the early stages of the grooming process. Differences in luring patterns exhibited by study participants could inform this process. Moreover, the use of community education focused on key grooming patterns can educate adults regarding what to look for, encourage them to take responsibility for children's safety, and empower them to act when concerned. This would be most helpful for strategies that may be less obvious, more manipulative, or appear more normal and therefore, may go unnoticed as potentially problematic. For example, programs educating parents and professionals working with youth may use patterns of luring strategies to provide information regarding what behaviors to be suspicious of in different contexts. They can be taught how offenders may differ in the strategies that they use to lure victims away for the purpose of committing CSA. Making adults more aware of potential luring patterns may increase the possibility that they will be able to intervene prior to the onset of abuse.

The current study could also inform conversations between adults and the children for whom they are responsible. As indicated by the participants in Budin and Johnson's (1989) study investigating offenders' perceptions about the efficacy of current prevention efforts, parents should be encouraged to ask questions about suspicious 
behavior. Learning about potential patterns of luring strategies used by CSA offenders may inform conversations and shape questions that parents and professionals utilize with children as a means of becoming knowledgeable about the types of interactions in which their children are involved. For example, based on the findings presented previously, adult offenders tend to bribe their victims with money more often than their adolescent counterparts. With this in mind, parents can be prepared to ask their children about unexplained money or store bought items.

As stated earlier, many cases of extra-familial CSA occur in youth-serving organizations (Kaufman, Tews, Schuett, \& Kaufman, 2012). The current study has implications for policy change within these organizations. Specifically, policies related staff and youth interactions may be informed by results indicating particular patterns of luring strategies by extra-familial CSA offenders and have been identified as a crucial component of successful prevention (Saul, Patterson, \& Audage, 2010). Additionally, supervision focused on identifying favoritism and gift-giving should be standard practice in reinforcing appropriate behaviors (Saul et al., 2010). For example, prohibiting the giving of money to youth members by staff would make this behavior stand out, if it were to occur. The same would be true of a staff member or volunteer who spent time alone with a child in an organization whose policies prohibited one to one time alone. When behaviors stand out, others are more likely to become suspicious of the interaction and there may be an increased chance of intervention prior to the onset of abuse. In addition, it has been found that adolescents consistently engage in a greater number of manipulative strategies. Therefore, a policy should be enforced that requires youth to 
travel (e.g., to the bathroom) in groups of more than two, to ensure that there are never two children alone in a secluded area. Finally, a review of youth-serving organizations in which CSA had occurred, identified a few characteristics, during the recruitment of staff and volunteers, which could safeguard against potential abuse. One of these safeguards was to have an explicit safeguarding culture with well-articulated values and behaviors (Cleary, 2012; Erooga, Allnock, \& Telford, 2012; Saul et al., 2010). Therefore, better education for organizational staff and volunteers regarding the grooming process (i.e., including luring) as well as the organization's clear commitment to actively preventing CSA can also strengthen their hiring practices. Offenders who see this commitment to youth safety are often encouraged to look elsewhere for employment.

The present study also has implications for the effectiveness of organizational training. Organizations can use knowledge about grooming practices (including luring) to educate their staff regarding "red flag" behaviors (i.e., high risk behaviors for abuse) on the part of youth, staff, volunteers, and visitors that merit closer tracking and/or supervision. Since policies are not always followed, it may be beneficial to train staff and volunteers more broadly on luring strategies as well as on potential victim's reactions to threats and coercion related to abuse overtures. Training of this nature may help encourage staff and volunteers to be on the lookout for such behaviors when policies are not being consistently implemented (Saul et al, 2010). For example, victims who have been threatened by an offender may exhibit more withdrawn behaviors due to concerns regarding the consequences with which they have been threatened. Learning what to look for can also empower supervisors to intervene more quickly, enhancing youth safety. 
Using research to inform organizational safety practices can benefit staff both in terms of particular behaviors to be "on the lookout for" as well as being more engaged in proactive efforts to maintain youth safety.

Finally, study findings may have implications for the treatment of CSA offenders. In relapse prevention (i.e., prevention of recidivism), a plan is created to assist the exoffender, who is participating in treatment, in recognizing and avoiding interaction and situations that trigger feelings, thoughts, and behaviors which may lead to offending behavior (Rich, 2003). A better understanding of the types of luring strategies that a particular offender has used in past offenses may suggest high risk situations that should be avoided in the future. Moreover, models of community reintegration, such as Circles of Support and Accountability (COSA), can utilize information from this study as part of its program. COSA uses volunteer community members to support an ex-offender through reintegration (Wilson, Cortoni, \& McWhinne, 2009). One of the core components of the COSA model is to ensure that the offender successfully completes relapse prevention programs (Wilson et al. 2009). Sharing past MO patterns with community treatment providers and individuals in an offender's life who are supporting community reintegration will offer these individuals a broader array of possible "red flag" behaviors that mark the need for early intervention. Addressing these types of early grooming behaviors can help prevent offender recidivism.

\section{Future Directions}

There are multiple avenues that future directions could take to forward this area of research. For example, consideration should be given to the possibility that strategies 
used to lure potential victims for the purpose of committing CSA are more dependent on victim characteristics than on offender characteristics. These victim characteristics have been found in previous research to have a significant effect on strategies used throughout the MO continuum. For example, Kaufman and his colleagues (1996) found that the use of drugs and alcohol as a grooming strategy increases linearly as victim age increases. It may be that the ability to tailor strategies to match victim characteristics is the more significant research avenue. Another example is illustrated by the fact that offenders often tailor their grooming strategies to the age of the victim (e.g., threats against a victim's family members are not used with victims too young to understand the concept). Therefore, the role of victim characteristics (e.g., victim age) in the selection of offenders' luring strategies should be explored in future research.

As alluded to above, the process of luring may be dependent on the location of, not only where the abuse took place, but also the location where the offender gained access to the victim. The item prompt that the participants responded to asked about the strategies that were used to get the victim to go with them. Luring, as it is operationalized in this study, may only be a process that occurs if the victim is moved. Therefore, this potential relationship should be investigated. For example, future research may look at the typography of strategies employed when the victim is lured from a public location to a private location. In this case, more subtle strategies may be used to reduce the chances that the process of luring is noticed by bystanders. Conversely, it may also be of value to explore the types of luring strategies used on victims who are already isolated, as well as contrasting these two, very different, luring presentations. Findings may have important 
implications for creating more effective safety approaches due to greater responsiveness to differential setting characteristics.

This study was also limited in its ability to identify CSA offenders who had both intra-familial and extra-familial victims. Therefore, future research may benefit from distinguishing these "mixed" offenders and exploring differences in MO between offenders who commit CSA solely against intra-familial or extra-familial victims and offenders who have both types of victims. This distinction is crucial to gaining a more complete understanding of how CSA offenders commit these crimes. One could argue that these "mixed" offenders may be the most sophisticated group, given their ability to offend across victim subtypes. As such, it is important to ensure a better understanding of this offender subgroup so that prevention programming can incorporate strategies to combat their abusive overtures to potential childhood victims.

Finally, other processes that comprise the MO timeline need to be further investigated. For example, there is limited, empirical knowledge involving how and where offenders gain access to their victims. By increasing knowledge in this particular MO process, prevention programs can inform parents and professionals of specific areas of which they should be more cautious of. For example, if it is found that extra-familial offenders commonly find victims by coaching youth sports, parents may increase their presence during these events and limit the opportunities that a coach has one to one time with their child. As different aspects of the MO continuum are investigated the field continues to gain insight into the processes that occur in the commission of CSA. The 
more insight the field has, the better prepared they are to create safer spaces and protect children.

This study attempted to address a current gap in the literature on the MO of CSA offenders. Previous literature focused on a limited number of time points on the MO continuum and has yet to create a comprehensive perspective on the grooming process. In particular, there has been a lack of research focusing on the strategies that offenders use to lure their victims away, for the purpose of committing CSA. Identifying patterns of luring strategies by different subgroups has significant implications for the prevention of CSA. As previously stated, much of the current research is aimed at the treatment of CSA offenders after the crime has occurred. The goal of this line of research is to strengthen prevention efforts. This study in particular attempted to contribute to the literature by identifying luring strategies used by various offender subgroups and to translate this information into strategies that community members, professionals and the staff/volunteers of youth serving organizations might use to interrupt offenders' grooming process. Findings suggested a number of specific luring patterns that have implication for prevention as well as treatment. 
Table 1.

Subgroup Cell Sizes N (\% of Total Sample)

\begin{tabular}{lccc}
\hline & Adolescent & Adult & Row Totals \\
\hline Intra-familial & $179(24.6)$ & $231(31.7)$ & $410(56.3)$ \\
Extra-familial & $189(26.0)$ & $129(17.7)$ & $318(43.7)$ \\
Column Totals & $368(50.6)$ & $360(49.4)$ & \\
\hline
\end{tabular}

Note: A chi-square goodness of fit test indicated that cell sizes relative to offender were not significantly different, $\chi^{2}(1, \mathrm{n}=728)=.088, p=.767$. However, chi-square goodness of fit tests also indicated that cell sizes were significantly different relative to offender-victim relationship, $\chi^{2}(1, \mathrm{n}=728)=11.626, p<.01$, and combined subgroups (e.g., adolescent intra-familial), $\chi^{2}(1, \mathrm{n}=728)=28.945, p<.001$. 
Table 2.

Luring the Victim to the Abuse Site Subscales

Using Bribes and Enticements to Lure the Victim to the Abuse Site (10 items)

Having a pet that they wanted to see or play with

Letting them see you with other children

Telling them that you would give them special rewards or privileges

Giving them toys or candy

Giving them money

Defending them when they were being bullied by other children

Telling them that one of the parents wanted them to go with you

Telling them that you could be trusted

Telling them that you were going to do something fun

Pretending to be someone they like or trust

Using Threats and Coercion (20 items)

Saying that since you were older, they should do what you say

Getting angry or violent with them

Letting them see you angry or violent with another person

Saying that you wouldn't spend time with them unless they come along

Saying that you will stop giving them special rewards unless they come along

Saying that you would get in trouble if they did not come along

Saying that they would get in trouble if they did not come along

Saying that you would hurt them if they did not come along

Saying that you would hurt their friends if they did not come along

Saying that you would hurt one of their family members if they did not come along

Saying that you would hurt their pet if they did not come along

Hoping they thought that you would hurt them even though you didn't say you would

Letting them know that you had hurt others or had a bad temper, so they were scared of you

Letting them see you had a weapon even though you didn't say you'd use it

Using physical force to make them come along

Hurting them

Hurting their pet

Hurting some other animal

Hurting a member of their family

Threatening them with a weapon

Alcohol and Drugs (3 items)

Giving them alcohol

Giving them cigarettes

Giving them drugs 
Table 3.

Group Means (Standard Deviations) for the 'Bribes and Enticements', Threats and Coercion', and 'Drugs and Alcohol' Subscales

\begin{tabular}{lccc}
\hline & $\begin{array}{c}\text { Bribes and } \\
\text { Enticements }\end{array}$ & $\begin{array}{c}\text { Threats and } \\
\text { Coercion }\end{array}$ & $\begin{array}{c}\text { Drugs and } \\
\text { Alcohol }\end{array}$ \\
\hline Adolescents & $.681(.038)$ & $.271(.022)$ & $.099(.021)$ \\
Adults & $.708(.039)$ & $.202(.022)$ & $.090(.022)$ \\
Intra-familial & $.741(.031)$ & $.269(.018)$ & $.077(.017)$ \\
Extra-familial & $.648(.036)$ & $.203(.021)$ & $.112(.020)$ \\
Adolescent/Intra-familial & $.763(.608)$ & $.324(.430)$ & $.077(.331)$ \\
Adolescent/Extra-familial & $.701(.661)$ & $.286(.454)$ & $.112(.370)$ \\
Adult/Intra-familial & $.693(.647)$ & $.196(.280)$ & $.068(.277)$ \\
Adult/Extra-familial & $.625(.590)$ & $.139(.223)$ & $.129(.405)$ \\
Overall & $.698(.653)$ & $.237(.372)$ & $.090(.333)$ \\
\hline
\end{tabular}


Table 4.

Percent of Participants Indicating Use of Specific Strategies by Adolescent and Adult CSA Offenders

\begin{tabular}{|c|c|c|}
\hline & Adolescents & Adult \\
\hline \multicolumn{3}{|l|}{ Drugs and Alcohol } \\
\hline Give them cigarettes & 8.2 & 5.6 \\
\hline Give them alcohol & 3.8 & 5.6 \\
\hline Give them drugs & 4.6 & 2.8 \\
\hline \multicolumn{3}{|l|}{ Bribes and Enticements } \\
\hline Tell them you will something fun* & 56.8 & 47.6 \\
\hline $\begin{array}{l}\text { Telling them they'd get special rewards } \\
\text { or privileges* }\end{array}$ & 53.1 & 45.1 \\
\hline Give them toys or candy* & 48.6 & 42.5 \\
\hline Tell them you can be trusted* & 46.5 & 44.7 \\
\hline Defend them from bullies* & 38.6 & 36.7 \\
\hline Give them money* & 27.5 & 38.9 \\
\hline Letting them see you with other children* & 18.3 & 19.4 \\
\hline Pretend to be someone they like or trust & 18.2 & 9.7 \\
\hline Tell them parents said to go with you & 17.9 & 9.2 \\
\hline Having a pet to show and play with & 5.8 & 7.0 \\
\hline \multicolumn{3}{|l|}{ Threats and Coercion } \\
\hline $\begin{array}{l}\text { Threaten with ending of privileges or } \\
\text { rewards* }\end{array}$ & 35.9 & 24.4 \\
\hline $\begin{array}{l}\text { Tell them you are older and they should } \\
\text { do what you say* }\end{array}$ & 31.8 & 23.9 \\
\hline $\begin{array}{l}\text { Tell them you won't spend time with } \\
\text { them if they didn't go* }\end{array}$ & 31.6 & 16.1 \\
\hline $\begin{array}{l}\text { Tell them they would get in trouble if } \\
\text { they didn't go* }\end{array}$ & 28.1 & 15.0 \\
\hline $\begin{array}{l}\text { Tell them you would get in trouble if they } \\
\text { didn't go }\end{array}$ & 24.5 & 10.8 \\
\hline $\begin{array}{l}\text { Let them see you angry or violent with } \\
\text { another person* }\end{array}$ & 23.4 & 23.3 \\
\hline Get angry or violent with them* & 22.3 & 18.1 \\
\hline $\begin{array}{l}\text { Hoping they thought you'd hurt them if } \\
\text { they didn't go }\end{array}$ & 21.3 & 9.4 \\
\hline Use physical force to make them go & 18.5 & 6.4 \\
\hline $\begin{array}{l}\text { Telling them you had hurt others or had a } \\
\text { bad temper }\end{array}$ & 16.3 & 10.8 \\
\hline $\begin{array}{l}\text { Tell them you would hurt them if they } \\
\text { didn't go }\end{array}$ & 15.5 & 4.4 \\
\hline Hurt them & 14.1 & 5.3 \\
\hline Tell them you'd hurt their family if they & 7.9 & 2.2 \\
\hline
\end{tabular}


didn't go

Let them see you had a weapon

Tell them you'd hurt their friends if they

didn't go

Threaten them with a weapon

Tell them you'd hurt their pet if they

didn't go

Tell them you'd hurt their pet if they

didn't go

Hurt a member of their family

Hurt their pet

Hurt some other animal
$6.5 \quad 3.1$

$6.4 \quad .8$

5.7

5.7

1.4

.3

$5.7 \quad .3$

$\begin{array}{ll}5.2 & 3.9\end{array}$

$3.8 \quad .6$

$3.0 \quad .6$

*at least $15 \%$ of participants in both groups (i.e., adolescents and adults) indicated using strategy

Note: Strategies are listed from highest endorsement, first by adolescents (first column), and then by adults (second column) within each subscale. 
Table 5.

Percent of Participants Indicating Use of Specific Strategies by Intra- and Extra-familial CSA Offenders

\begin{tabular}{|c|c|c|}
\hline & Intra-familial & Extra-familial \\
\hline \multicolumn{3}{|l|}{ Drugs and Alcohol } \\
\hline Give them cigarettes & 5.1 & 9.1 \\
\hline Give them alcohol & 3.7 & 6.0 \\
\hline Give them drugs & 2.7 & 4.7 \\
\hline \multicolumn{3}{|l|}{ Bribes and Enticements } \\
\hline $\begin{array}{l}\text { Telling them they'd get special rewards } \\
\text { or privileges* }\end{array}$ & 54.5 & 42.3 \\
\hline Tell them you will something fun* & 52.7 & 51.7 \\
\hline Give them toys or candy* & 51.0 & 38.7 \\
\hline Tell them you can be trusted* & 45.4 & 45.9 \\
\hline Defend them from bullies* & 39.8 & 34.9 \\
\hline Give them money* & 34.7 & 31.1 \\
\hline Letting them see you with other children* & 17.1 & 21.1 \\
\hline Tell them parents said to go with you & 12.0 & 15.7 \\
\hline Pretend to be someone they like or trust & 10.5 & 18.6 \\
\hline Having a pet to show and play with & 8.3 & 15.5 \\
\hline \multicolumn{3}{|l|}{ Threats and Coercion } \\
\hline $\begin{array}{l}\text { Threaten with ending of privileges or } \\
\text { rewards* }\end{array}$ & 34.4 & 24.8 \\
\hline $\begin{array}{l}\text { Tell them you are older and they should } \\
\text { do what you say* }\end{array}$ & 28.3 & 27.4 \\
\hline $\begin{array}{l}\text { Let them see you angry or violent with } \\
\text { another person* }\end{array}$ & 27.8 & 18.6 \\
\hline $\begin{array}{l}\text { Tell them you won't spend time with } \\
\text { them if they didn't go* }\end{array}$ & 23.4 & 24.6 \\
\hline $\begin{array}{l}\text { Tell them they would get in trouble if } \\
\text { they didn't go* }\end{array}$ & 23.0 & 19.8 \\
\hline Get angry or violent with them* & 22.4 & 17.3 \\
\hline $\begin{array}{l}\text { Tell them you would get in trouble if they } \\
\text { didn't go* }\end{array}$ & 18.3 & 17.0 \\
\hline $\begin{array}{l}\text { Hoping they thought you'd hurt them if } \\
\text { they didn't go }\end{array}$ & 16.0 & 14.8 \\
\hline $\begin{array}{l}\text { Telling them you had hurt others or had a } \\
\text { bad temper }\end{array}$ & 15.4 & 11.3 \\
\hline Use physical force to make them go & 11.5 & 13.8 \\
\hline Hurt them & 8.5 & 11.3 \\
\hline Hurt a member of their family & 5.1 & 3.8 \\
\hline Let them see you had a weapon & 4.6 & 5.0 \\
\hline Tell them you'd hurt their family if they & 3.4 & 7.2 \\
\hline
\end{tabular}


didn't go

Tell them you would hurt them if they

didn't go

Tell them you'd hurt their friends if they

2.7

5.0

didn't go

Threaten them with a weapon

2.7

4.7

Tell them you'd hurt their pet if they

didn't go

Hurt their pet

1.5

3.1

Hurt some other animal

1.5

*At least $15 \%$ of participants in both groups (i.e., intra- and extra-familial) indicated using strategy

Note: Strategies are listed from highest endorsement, first by adolescents (first column), and then by adults (second column) within each subscale. 
Table 6.

t-test of Group Differences in Adolescent and Adult CSA Offenders on Selected Items

\begin{tabular}{|c|c|c|c|c|c|}
\hline & df & $t$-value & $p$-value & $\begin{array}{l}\text { Adolescents } \\
\text { Means (SD) }\end{array}$ & $\begin{array}{c}\text { Adults } \\
\text { Means (SD) }\end{array}$ \\
\hline \multicolumn{6}{|l|}{ Bribes and Enticements } \\
\hline $\begin{array}{l}\text { Tell them you will do } \\
\text { something fun }\end{array}$ & 725 & 2.298 & .022 & $\begin{array}{c}1.264 \\
(1.217)\end{array}$ & $\begin{array}{l}1.056 \\
(1.222)\end{array}$ \\
\hline $\begin{array}{l}\text { Tell them you can be } \\
\text { trusted }\end{array}$ & 726 & -.402 & .688 & $\begin{array}{c}1.03 \\
(1.199)\end{array}$ & $\begin{array}{c}1.069 \\
(1.272)\end{array}$ \\
\hline $\begin{array}{l}\text { Defend them from } \\
\text { bullies }\end{array}$ & 726 & -.777 & .437 & $\begin{array}{c}.766 \\
(1.059)\end{array}$ & $.831(1.169)$ \\
\hline Give them money & 725 & -3.474 & $.001 *$ & $.550(.968)$ & $.819(1.116)$ \\
\hline $\begin{array}{l}\text { Letting them see you } \\
\text { with other children }\end{array}$ & 725 & -1.471 & .142 & $.313(.726)$ & $.400(.858)$ \\
\hline $\begin{array}{l}\text { Telling them they'd get } \\
\text { special rewards or } \\
\text { privileges }\end{array}$ & 724 & 1.726 & .085 & $\begin{array}{c}1.215 \\
(1.248)\end{array}$ & $\begin{array}{c}1.056 \\
(1.243)\end{array}$ \\
\hline $\begin{array}{l}\text { Give them toys or } \\
\text { candy }\end{array}$ & 724 & 1.723 & .085 & $\begin{array}{c}1.114 \\
(1.240)\end{array}$ & $.958(1.206)$ \\
\hline \multicolumn{6}{|l|}{ Threats and Coercion } \\
\hline $\begin{array}{l}\text { Tell them you are older } \\
\text { and they should do } \\
\text { what you say }\end{array}$ & 726 & 1.605 & .109 & $.614(.992)$ & $.497(.973)$ \\
\hline $\begin{array}{l}\text { Get angry or violent } \\
\text { with them }\end{array}$ & 726 & 1.281 & .201 & $.394(.811)$ & $.319(.758)$ \\
\hline $\begin{array}{l}\text { Let them see you angry } \\
\text { or violent with another } \\
\text { person }\end{array}$ & 726 & .476 & .634 & $.467(.921)$ & $.436(.849)$ \\
\hline $\begin{array}{l}\text { Tell them you won't } \\
\text { spend time with them if } \\
\text { they didn't go }\end{array}$ & 725 & 4.373 & $.000 *$ & $.572(.935)$ & $.297(.749)$ \\
\hline $\begin{array}{l}\text { Threaten with ending of } \\
\text { privileges or rewards }\end{array}$ & 726 & 3.115 & $.0018 *$ & $\begin{array}{c}.723 \\
(1.059)\end{array}$ & $.492(.938)$ \\
\hline $\begin{array}{l}\text { Tell them they would } \\
\text { get in trouble if they } \\
\text { didn't go }\end{array}$ & 725 & 3.722 & $.000 *$ & $.526(.926)$ & $.292(.762)$ \\
\hline
\end{tabular}

Note: $t$-tests were only run on items that were endorsed by at least $15 \%$ of both groups as indicated by Table 4. 
Table 7.

t-test of Group Differences in Intra- and Extra-familial CSA Offenders on Selected Items

\begin{tabular}{|c|c|c|c|c|c|}
\hline & df & $t$-value & $p$-value & $\begin{array}{c}\text { Intra- } \\
\text { familial } \\
\text { Means (SD) }\end{array}$ & $\begin{array}{c}\text { Extra- } \\
\text { familial } \\
\text { Means (SD) }\end{array}$ \\
\hline \multicolumn{6}{|l|}{ Bribes and Enticements } \\
\hline $\begin{array}{l}\text { Tell them you will do } \\
\text { something fun }\end{array}$ & 725 & -.368 & .713 & $\begin{array}{c}1.176 \\
(1.235)\end{array}$ & $\begin{array}{c}1.142 \\
(1.210)\end{array}$ \\
\hline $\begin{array}{l}\text { Tell them you can be } \\
\text { trusted }\end{array}$ & 726 & -.373 & -710 & $\begin{array}{c}1.066 \\
(1.252)\end{array}$ & $\begin{array}{c}1.031 \\
(1.215)\end{array}$ \\
\hline $\begin{array}{l}\text { Defend them from } \\
\text { bullies }\end{array}$ & 726 & -1.462 & .144 & $.851(1.140)$ & $.730(1.079)$ \\
\hline Give them money & 725 & -.952 & .341 & $.716(1.061$ & $.642(1.040)$ \\
\hline $\begin{array}{l}\text { Letting them see you } \\
\text { with other children }\end{array}$ & 725 & 1.007 & .314 & $.330(.777)$ & $.390(817)$ \\
\hline $\begin{array}{l}\text { Telling them they'd get } \\
\text { special rewards or } \\
\text { privileges }\end{array}$ & 724 & -4.015 & $.000 *$ & $\begin{array}{c}1.298 \\
(1.275)\end{array}$ & $.927(1.179)$ \\
\hline $\begin{array}{l}\text { Give them toys or } \\
\text { candy }\end{array}$ & 724 & -2.936 & .003 & $\begin{array}{c}1.154 \\
(1.237)\end{array}$ & $.887(1.194)$ \\
\hline \multicolumn{6}{|l|}{ Threats and Coercion } \\
\hline $\begin{array}{l}\text { Tell them you are older } \\
\text { and they should do } \\
\text { what you say }\end{array}$ & 726 & -.828 & .408 & $.583(1.015)$ & $.522(.942)$ \\
\hline $\begin{array}{l}\text { Get angry or violent } \\
\text { with them }\end{array}$ & 726 & -1.577 & .115 & $.398(.819)$ & $.305(.740)$ \\
\hline $\begin{array}{l}\text { Let them see you angry } \\
\text { or violent with another } \\
\text { person }\end{array}$ & 726 & -2.944 & .003 & $.537(.938)$ & $.343(.801)$ \\
\hline $\begin{array}{l}\text { Tell them you won't } \\
\text { spend time with them if } \\
\text { they didn't go }\end{array}$ & 725 & .155 & .877 & $.432(.860)$ & $.442(.857)$ \\
\hline $\begin{array}{l}\text { Threaten with ending of } \\
\text { privileges or rewards }\end{array}$ & 726 & -3.098 & $.0016 *$ & $.710(1.066)$ & $.478(.911)$ \\
\hline $\begin{array}{l}\text { Tell them you would } \\
\text { get in trouble if they } \\
\text { didn't go }\end{array}$ & 725 & -.793 & .428 & $.330(.771)$ & $.286(.699)$ \\
\hline $\begin{array}{l}\text { Tell them they would } \\
\text { get in trouble if they } \\
\text { didn't go }\end{array}$ & 725 & -1.254 & .210 & $.445(.895)$ & $.365(.802)$ \\
\hline
\end{tabular}

Note: $t$-tests were only run on items that were endorsed by at least $15 \%$ of both groups as indicated by Table 5. 
Figure 1.

The Ecological Model.

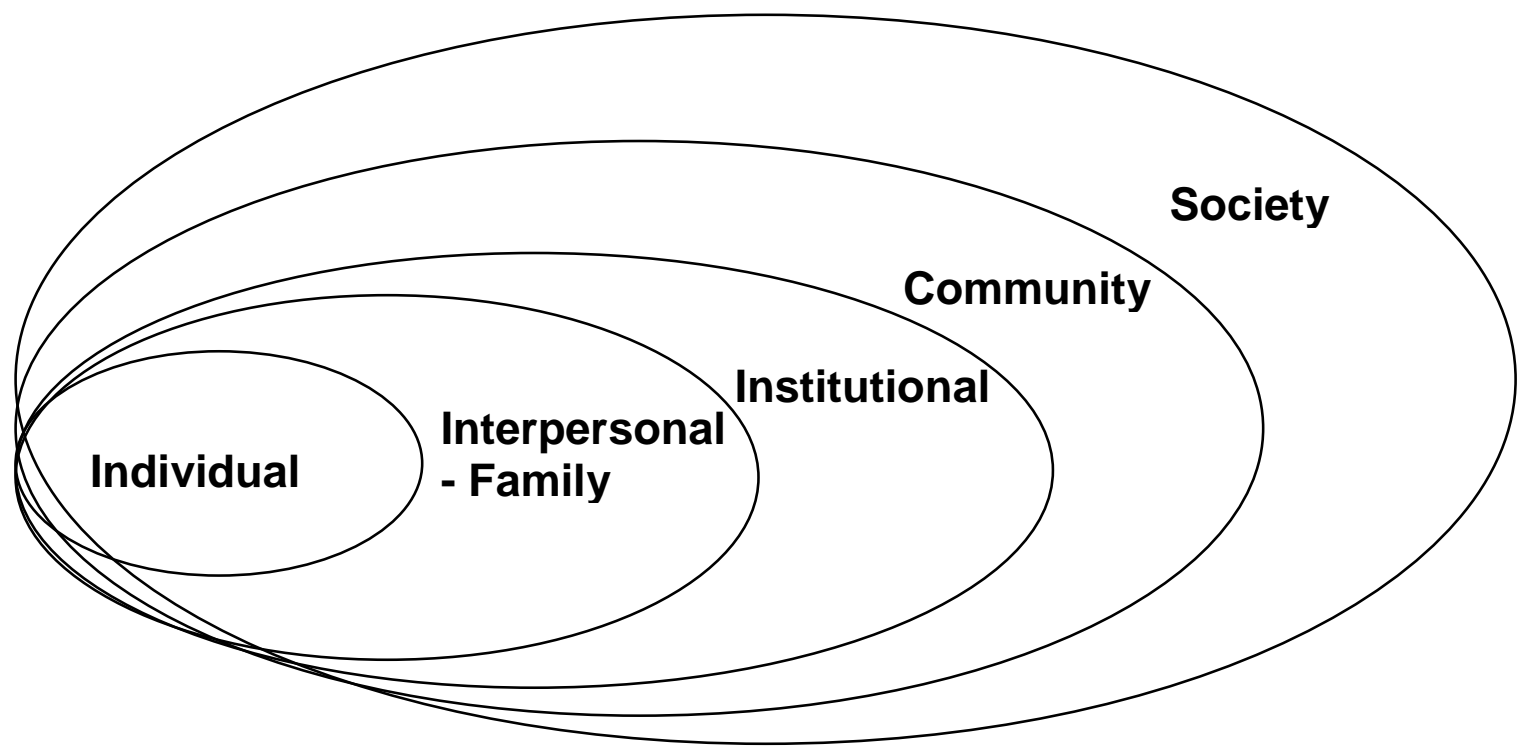


Figure 2.

Moderation Model (Hypotheses $3 a$ and 3b).

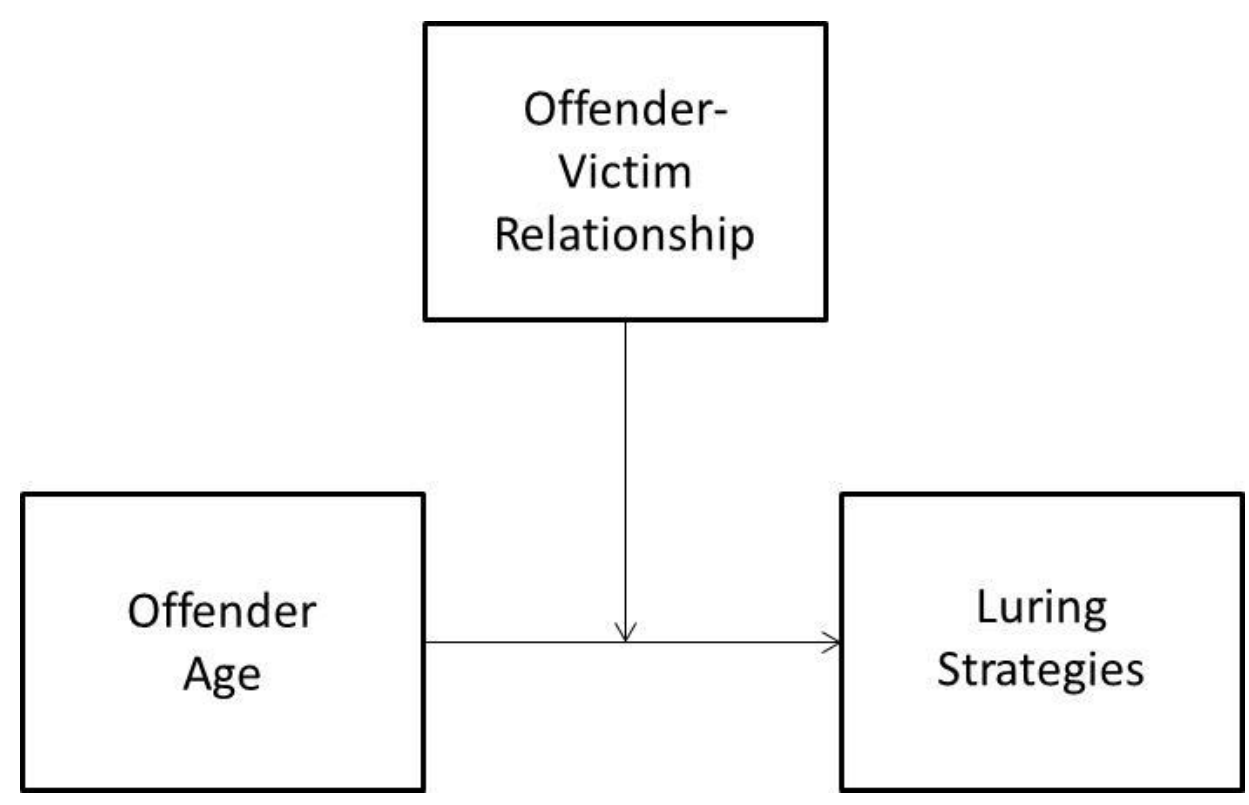


Figure 3 .

Mean 'Threats and Coerion' Subscale Scores as a Function of Offender Age (Adolescent or Adult).

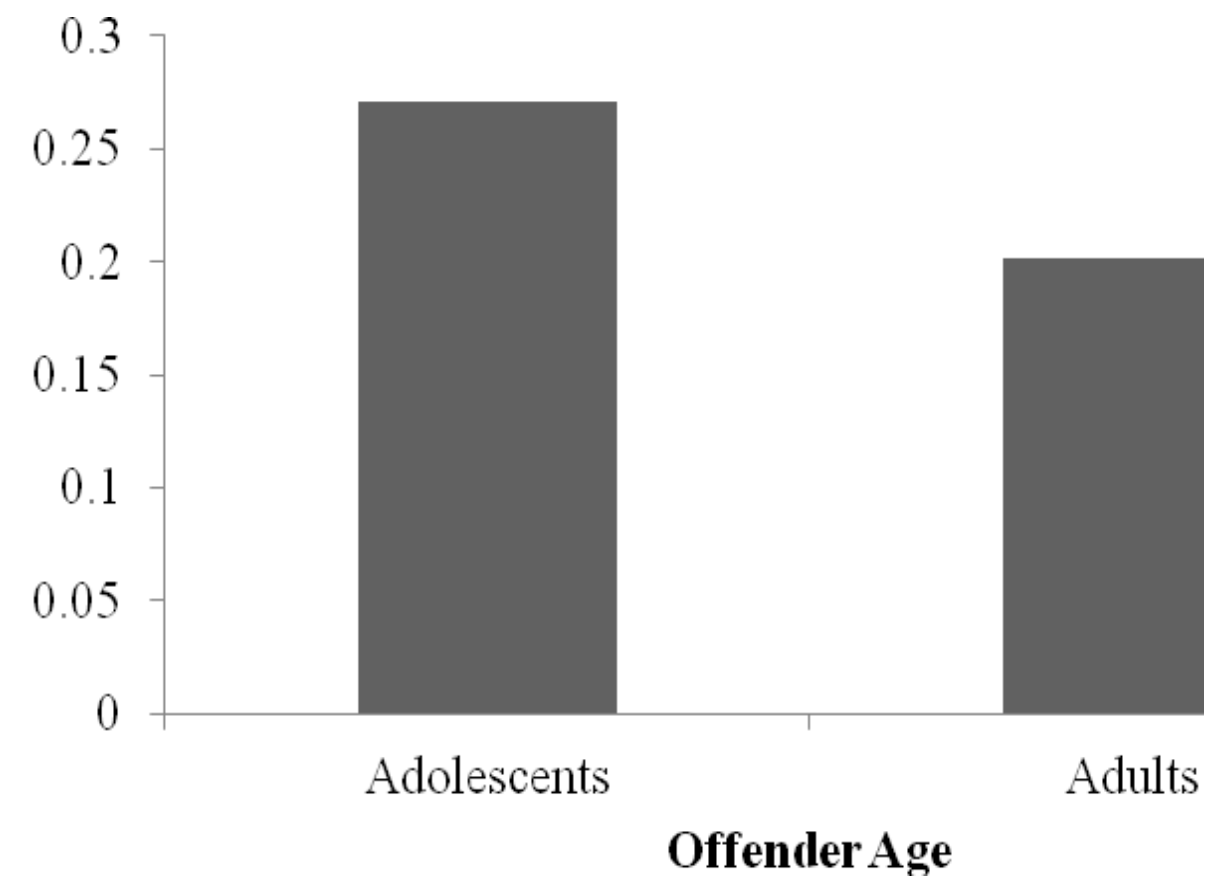


Figure 4.

Mean 'Threats and Coercion' Subscale Scores as a Function of Offender-Victim Relationship (Intra- or Extra-familial).

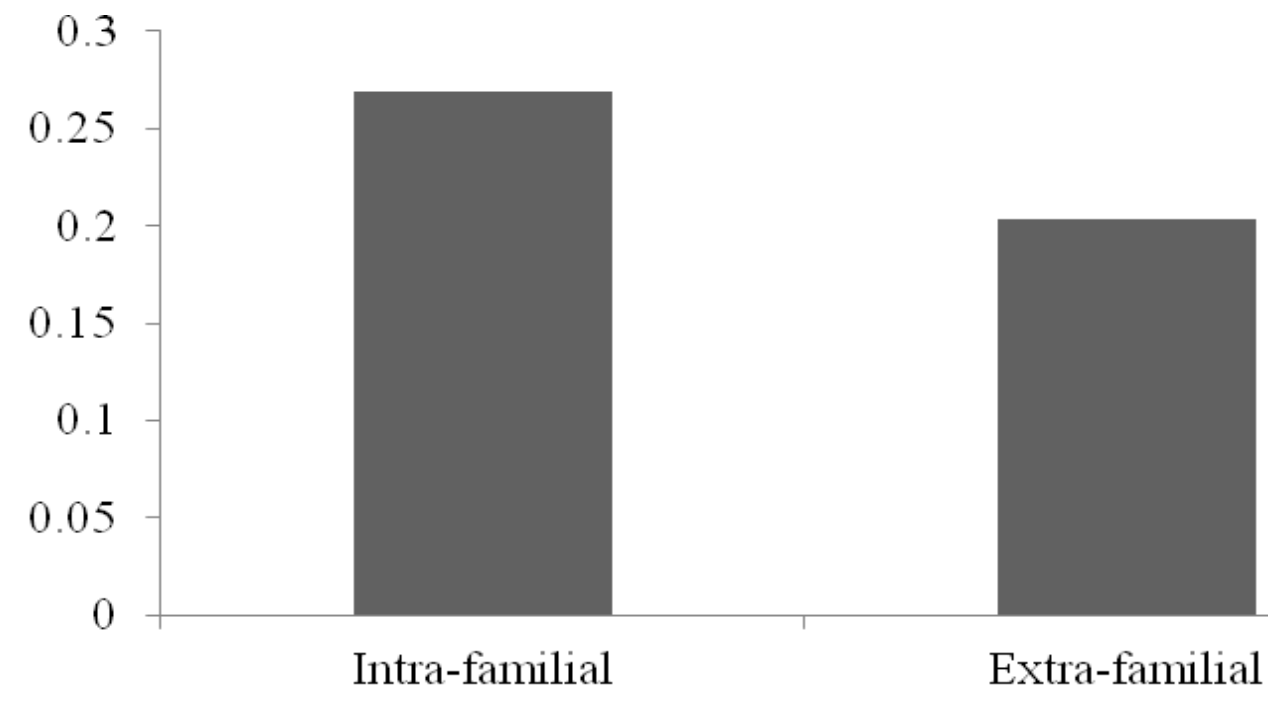

Offender-Victim Relationship 


\section{References}

Abel, G.G., Becker, J.V., Mittelman, M., Cunningham-Rathner, J., Rouleau, J.L., \& Murphy, W.D. (1987). Self-reported sex crimes of nonincarcerated paraphilics. Journal of Interpersonal Violence, 2(1), 3-25.

Abel, G.G., Osborn, C.A., \& Twigg, D.A. (1993). Sexual assualt through the life span: Adult offenders with juvenile histories. In H.E. Barbaree, W.L. Marshall, \& S.M. Hudson (Eds.), The juvenile sex offender. (pp. 104-117) New York, N.Y.: The Guilford Press.

Beitchman, J.H., Zucker, K.J., Hood, J.E., DaCosta, G.A., Akman, D, \& Cassavia, E. (1992). A review of the long-term effects of child sexual abuse. Child Abuse \& Neglect, 16, 101-118.

Berliner, L. \& Conte, J.R. (1990). The process of victimization: The victims' perspective. Child Abuse \& Neglect, 14, 29-40.

Bolen, R. (2001). Child sexual abuse: Its scope and our failure. New York, N.Y.: Kluwer Academic/Plenum Publishers

Bronfenbrenner, U. (1979). The ecology of human development: Experiments by nature and design. Cambridge, MA: Harvard University Press.

Browne, A. \& Finkelhor, D. (1986). Impact of child sexual abuse: a review of the research. Psychological Bulletin, 99(1), 66-77.

Budin, L.E. \& Johnson, C.F. (1989). Sex abuse prevention programs: Offenders' attitudes about their efficacy. Child Abuse \& Neglect, 13, 77-87. 
Butts, J.A. \& Mears, D.P. (2001). Reviving juvenile justice in a get-tough era. Youth \& Society, 33(2), 169-198.

Centers for Disease Control and Prevention. (2004). Sexual violence prevention:

Beginning the dialogue. Atlanta, GA: Centers for Disease Control and Prevention.

Chaffin, M. (2008). Our minds are made up-Don't confuse us with the facts:

Commentary on policies concerning children with sexual behavior problems and juvenile sex offenders. Child Maltreatment, 13(2), 110-121.

Clarke, R.V. \& Cornish, D.B. (1985). Modeling offenders' decisions: A framework for research and policy. Crime and Justice, 6, 147-185.

Cleary, K. (2012). Safer recruitment - guidance for organizations. In M. Erooga (Ed.) Towards safer organizations - Practical steps to prevent the abuse of children by those working with them. London, England: Wiley Press, Inc.

Conte, J.R., Wolf, S., \& Smith, T. (1989). What sexual offenders tell us about prevention strategies. Child Abuse \& Neglect, 13, 293-301.

Cornish, D. B., \& Clarke, R. V. (1986). Introduction. In D.B. Cornish \& R.V. Clarke (Eds.), The reasoning criminal: Rational choice perspectives on offending. (pp. 116) New York, N.Y.: Springer-Verlag New York Inc.

Cornish, D. B., \& Clarke, R. V. (2002). Analyzing organized crimes. In A. R. Piquero \& S.G.

Tibbetts (Eds.), Rational choice and criminal behavior: Recent research and future challenges (pp. 41-63). New York: Routledge. 
Elliot, D.M., \& Briere, J. (1995). Posttraumatic stress associated with delayed recall of sexual abuse: A general population study. Journal of Traumatic Stress Studies, 8, 629-648.

Elliot, M., Browne, K., \& Kilcoyne, J. (1995). Child sexual abuse prevention: What offenders tell us. Child Abuse \& Neglect, 19(5), 579-594.

Erooga, M., Allnock, D, \& Telford, P. (2012). Sexual abuse of children by people in organisations: What offenders can teach us about protection. In M. Erooga (Ed.) Towards safer organizations - Practical steps to prevent the abuse of children by those working with them. London, England: Wiley Press, Inc.

Finkelhor, D. (1994). Current Information on the Scope and Nature of Child Sexual Abuse. The Future of Children, 4(2), 31-53.

Finkelhor, D. \& Jones, L. (2006). Why have child maltreatment and child victimization declined? Journal of Social Issues, 62(4), 685-716.

Finkelhor, D., Ormrod, R., \& Chaffin, M. (2009). Juveniles who commit sex offenses against minors. U.S. Department of Justice, Office of Justice Programs, Office of Juvenile Justice and Delinquency Prevention. Washington, DC.

Fischer, D.G. \& McDonald, W.L. (1998). Characteristics of intrafamilial and extrafamilial child sexual abuse. Child Abuse \& Neglect, 22(9), 915-929.

Gallagher, B., Bradford, M., \& Pease, K. (2008). Attempted and completed incidents of stranger-perpetrated child sexual and abduction. Child Abuse and Neglect, 32, 517-528. 
Gibson, L.E. \& Leitenberg, H. (2000). Child sexual abuse prevention programs: Do they decrease the occurrence of child sexual abuse? Child Abuse \& Neglect, 24(9), 1115-1125.

Jaccard, J., Blanton, H., \& Dodge, T. (2005). Peer influences on risk behavior: An analysis of the effects of a close friend. Developmental Psychology, 41, 135-147.

Jewkes, R., Sen, P., \& Garcia-Moreno, P. (2002). Sexual violence. In Krug E.G. et al. (Eds.), World report on violence and health (148-181). Geneva: World Health Organization.

Johnson, C.F. (2004). Child sexual abuse. The Lancet, 364, 462-470.

Kaufman, K.L. (1994). Modus Operandi Questionnaire. Revised Version. Columbus, Ohio: Author. (Children's Hospital).

Kaufman, K.L., Hilliker, D.R., \& Daleiden, E.L. (1996). Subgroup differences in the modus operandi of adolescent sexual offenders. Child Maltreatment, 1, 17-24.

Kaufman, K.L., Hilliker, D.R., Lahtrop, P., Daleiden, E.L., \& Rudy, L. (1996). Sexual offenders' modus operandi: A comparison of structured interview and questionnaire approaches. Journal of Interpersonal Violence, 11(1), 19-34.

Kaufman, K.L., Holmberg, J.K., Orts, K.A., McCrady, F.E., Rotzien, A.L., Daleiden, E.L., \& Hilliker, D.R. (1998). Factors influencing sexual offenders' modus operandi: An examination of victim-offender relatedness and age. Child Maltreatment, 3, 349-361.

Kaufman, K.L., Mosher, H., Carter, M., \& Estes, L. (2006). An empirically based situational prevention model for child sexual abuse. In R.Wortley \& S. Smallbone 
(Eds.) Situational prevention of child sexual abuse. Monsey, NY: Criminal Justice Press.

Kaufman, K.L. \& Patterson, L.B. (2010). Using sex offenders' modus operandi to plan more effective prevention programs. In K.L. Kaufman (Ed.) The prevention of sexual violence: A practitioner's sourcebook. Holyoke, MA: NEARI Press.

Kaufman, K., Patterson, L., Hayes, A., Tews, H., \& Schuett, J. (2012). Strategies for enhancing Interpol's sexual violence prevention efforts. The Interpol Member's Operations Manual. Leone, France.

Kaufman, K., Tews, H., Schuett, J., \& Kaufman, B. (2012). Prevention is better than cure: The value of situational prevention in organizations. In M. Erooga (Ed.) Towards safer organizations - Practical steps to prevent the abuse of children by those working with them. London, England: Wiley Press, Inc.

Kaufman, K.L., Wallace, A.M., Johnson, C.F., \& Reeder, M.L. (1995). Comparing female and male perpetrators' modus operandi: Victims' reports of sexual abuse. Journal of Interpersonal Violence, 10, 322-333.

Kelley, S.J., Brant, R., \& Waterman, J. (1993). Sexual abuse of children in day care centers. Child Abuse \& Neglect, 17, 71-89.

Kelly, J.G., Ryan, A.M., Altman, B.E., \& Stelzner, S.R. (2000). Understanding and changing social systems: An ecological view. In J. Rappaport \& E. Seidman (Eds.) Handbook of community psychology. New York: Plenum Press. 
Kempf-Leonard, K. (2007). Minority youths and juvenile justice: Disproportionate minority contact after nearly 20 years of reform efforts. Youth Violence and Juvenile Justice, 5(1), 71-87.

Kolko, D.J. (1988). Educational programs to promote awareness and prevention of child sexual victimization: A review and methodological critique. Clinical Psychology Review, 8(2), 195-209.

Lang, R.A. \& Frenzel, R.R. (1988). How sex offenders lure children. Annals of Sex Research, 1, 303-317.

LeClrec, B., Beauregard, E. \& Proulx, J. (2008). Modus operandi and situational aspects in adolescent sexual offenses against children: A further examination. International Journal of Offender Therapy and Comparative Criminology, 52, 4661.

LeClerc, B., Proulx, J. \& McKibben, A. (2005). Modus operandi of sexual offenders working or doing voluntary work with children and adolescent. Journal of Sexual Aggression, 11(2), 187-195.

LeClerc, B. and Tremblay, P. (2007). Strategic behavior in adolescent sexual offenses against children: Linking modus operandi to sexual behaviors. Sexual Abuse: A Journal of Research and Treatment, 19, 23-41.

LeClerc, B., Proulx, J., \& Beauregard, E. (2009). Examining the modus operandi of sexual offenders against children and its practical implications. Aggression and Violent Behavior, 14, 5-12. 
Mcalinden, A.M. (2006). 'Setting 'em up': Personal familial and institutional grooming in the sexual abuse of children. Social and Legal Studies, 15(3), 339-362.

McMahon, P.M. \& Puett, R.C. (1999). Child sexual abuse as a public health issue: Recommendations of an expert panel. Sexual Abuse: A Journal of Research and Treatment, 11(4), 257-266.

Michaud, P. \& Proulx, J. (2009). Penile-response profiles of sexual aggressors during phallometric testing. Sexual Abuse: A Journal of Research and Treatment, 21(3), 308-334.

Miranda, A.O. \& Corcoran, C.L. (2000). Comparison of perpetration characteristics between male juvenile and adult sexual offenders: Preliminary results. Sex Abuse, 12(3), 179-188.

Orchowski, L.M., Gidycz, C.A., \& Murphy, M.J. (2010). Preventing campus-based sexual violence. In K.L. Kaufman (Ed.) The prevention of sexual violence: A practitioner's sourcebook. Holyoke, MA: NEARI Press.

Paolucci, E.O, Genuis, M.L., \& Violato, C. (2001). A meta-analysis of the published research on the effects of child sexual abuse. The Journal of Psychology, 135(1), $17-36$.

Pratt, T.C. (2008). Rational choice theory, crime control policy, and criminological relevance. Criminology \& Public Policy, 7(1), 43-52.

Remmers, H.H. \& Adkins, R.M. (1942) Reliability of multiple-choice measuring instruments, a function of the spearman brown prophecy formula, vi. The Journal of Educational Psychology,33, 385-390. 
Renk, K., Liljequist, L., Steinberg, A., Bosco, G., \& Phares, V (2002). Prevention of child sexual abuse: Are we doing enough? Trauma, Violence and Abuse, 3(1), 6884.

Reppucci, N.D. \& Haugaard, J.J. (1989). Prevention of child sexual abuse. Myth or reality. The American Psychologist, 44(10), 1266-75.

Rich, P. (2003). Understanding, assessing, and rehabilitating juvenile sexual offenders. Hoboken, NJ: John Wiley \& Sons, Inc.

Rowan, E. L. (2006). Understanding child sexual abuse. Jackson: University of Mississippi Press.

Russell, D.E.H. (1983). The incidence and prevalence of intrafamilial and extrafamilial sexual abuse of female children. Child Abuse and Neglect, 7, 133-146.

Saul, J., Patterson, J, \& Audage, N. (2010). Preventing sexual maltreatment in youthserving community organizations. In K.L. Kaufman (Ed.) The prevention of sexual violence: A practitioner's sourcebook. Holyoke, MA: NEARI Press.

Sedlak, A.J., Mettenburg, J., Basena, M., Petta, I., McPherson, K., Greene, A., and Li, S. (2010). Fourth National Incidence Study of Child Abuse and Neglect (NIS-4): Report to Congress, Executive Summary. Washington, DC: U.S. Department of Health and Human Services, Administration for Children and Families.

Seto, M.C. (2009). Pedophilia. Annual Review of Clinical Psychology, 5, 391-407.

Smallbone, S., Marshall, W.L., \& Wortley, R. (2008). Preventing child sexual abuse: Evidence, policy and practice. Portland, OR: Willan Publishing. 
Smallbone, S. \& Wortley, R. (2000). Child sexual abuse in queensland: Offender characteristics \& modus operandi, Queensland: Queensland Crime Commission and the Criminology Research Council.

Snyder, H.N. (2000). Sexual assault of young children as reported to law enforcement: Victim, incident, and offender characteristics, Washington DC: U.S. Department of Justice, Office of Justice Programs.

Snyder, H., \& Sickmund, M. (1999). Juvenile offenders and victims: 1999 national report. Washington, DC: Office of Juvenile Justice and Delinquency Prevention.

Steinberg, L. (2009). Adolescent development and juvenile justice. Annual Review of Clinical Psychology, 5, 459-485.

Steinberg, L., Chung, H.L., \& Little, M. (2004). Reentry of young offenders from the justice system: A developmental perspective. Youth Violence and Juvenile Justice, 2(1), 21-38.

Sullivan, J. \& Beech, A. (2004). A comparative study of demographic data relating to intra- and extra-familial child sexual abusers and professional perpetrators. Journal of Sexual Aggression, 10(1), 39-50.

Taylor-Browne, J. (1997). Obfuscating child sexual abuse II: Listening to survivors. Child Abuse Review, 6, 119-127.

Toft, S. \& Fellner, J. (2007). No easy answers: Sex offender laws in the US. (Vol. 19). Human Rights Watch. 
Trickett, P.K., Noll, J.G., Reiffman, A., \& Putnam, F.W. (2001). Variants of intrafamilial sexual abuse experience: Implications for short- and long-term development. Development and Psychopathology, 13, 1001-1019.

U.S. Department of Health \& Human Services. (no date). Maturation of the prefrontal cortex. Washington DC: U.S. Department of Health and Human Services, Office of Population Affairs.

Veneziano, C.M. \& Veneziano, L. (2002). Adolescent sex offenders: A review of the literature. Trauma, Violence, \& Abuse, 3, 247-260.

WHO. (2006). Preventing child maltreatment: A guide to taking action and generating evidence. World Health Organization.

Wilson, R.J., Cortoni, F., \& McWhinnie, A.J. (2009). Circles of support \& accountability: A canadian national replication of outcome findings. Sexual Abuse: A Journal of Research and Treatment, 21, 412-430.

Wortley, R. \& Smallbone, S. (2006). Applying situational principles to sexual offenses against children. In R.Wortley \& S. Smallbone (Eds.) Situational prevention of child sexual abuse. Monsey, NY: Criminal Justice Press.

Wurtele, S.K. \& Kenny, M.C. (2010). Primary prevention of child sexual abuse: Childand parent-focused approaches. In K.L. Kaufman (Ed.) The prevention of sexual violence: A practitioner's sourcebook. Holyoke, MA: NEARI Press.

Young, S. (1997). The use of normalization as a strategy in the sexual exploitation of children by adult offenders. The Canadian Journal of Human Sexuality, 6, 285295. 